\title{
Transgenic mice expressing tunable levels of DUX4 develop characteristic facioscapulohumeral muscular dystrophy- like pathophysiology ranging in severity
}

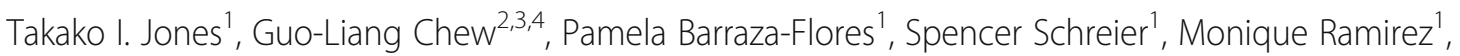
Ryan D. Wuebbles ${ }^{1}$, Dean J. Burkin ${ }^{1}$, Robert K. Bradley ${ }^{2,3}$ and Peter L. Jones ${ }^{1^{*}}$

\begin{abstract}
Background: All types of facioscapulohumeral muscular dystrophy (FSHD) are caused by the aberrant activation of the somatically silent DUX4 gene, the expression of which initiates a cascade of cellular events ultimately leading to FSHD pathophysiology. Typically, progressive skeletal muscle weakness becomes noticeable in the second or third decade of life, yet there are many individuals who are genetically FSHD but develop symptoms much later in life or remain relatively asymptomatic throughout their lives. Conversely, FSHD may clinically present prior to 5-10 years of age, ultimately manifesting as a severe early-onset form of the disease. These phenotypic differences are thought to be due to the timing and levels of DUX4 misexpression.
\end{abstract}

Methods: FSHD is a dominant gain-of-function disease that is amenable to modeling by DUX4 overexpression. We have recently created a line of conditional DUX4 transgenic mice, FLEXDUX4, that develop a myopathy upon induction of human DUX4-fl expression in skeletal muscle. Here, we use the FLEXDUX4 mouse crossed with the skeletal muscle-specific and tamoxifen-inducible line ACTA1-MerCreMer to generate a highly versatile bi-transgenic mouse model with chronic, low-level DUX4-fl expression and cumulative mild FSHD-like pathology that can be reproducibly induced to develop more severe pathology via tamoxifen induction of DUX4-fl in skeletal muscles.

Results: We identified conditions to generate FSHD-like models exhibiting reproducibly mild, moderate, or severe DUX4-dependent pathophysiology and characterized progression of pathology. We assayed DUX4-fl mRNA and protein levels, fitness, strength, global gene expression, and histopathology, all of which are consistent with an FSHD-like myopathic phenotype. Importantly, we identified sex-specific and muscle-specific differences that should be considered when using these models for preclinical studies.

(Continued on next page)

\footnotetext{
*Correspondence: peterjones@med.unr.edu

'Department of Pharmacology, School of Medicine, University of Nevada, Reno, Reno, NV 89557, USA

Full list of author information is available at the end of the article
}

(c) The Author(s). 2020 Open Access This article is licensed under a Creative Commons Attribution 4.0 International License, which permits use, sharing, adaptation, distribution and reproduction in any medium or format, as long as you give appropriate credit to the original author(s) and the source, provide a link to the Creative Commons licence, and indicate if changes were made. The images or other third party material in this article are included in the article's Creative Commons licence, unless indicated otherwise in a credit line to the material. If material is not included in the article's Creative Commons licence and your intended use is not permitted by statutory regulation or exceeds the permitted use, you will need to obtain permission directly from the copyright holder. To view a copy of this licence, visit http://creativecommons.org/licenses/by/4.0/ The Creative Commons Public Domain Dedication waiver (http://creativecommons.org/publicdomain/zero/1.0/) applies to the data made available in this article, unless otherwise stated in a credit line to the data. 
(Continued from previous page)

Conclusions: The ACTA1-MCM;FLEXDUX4 bi-transgenic mouse model has mild FSHD-like pathology and detectable muscle weakness. The onset and progression of more severe DUX4-dependent pathologies can be controlled via tamoxifen injection to increase the levels of mosaic DUX4-fl expression, providing consistent and readily screenable phenotypes for assessing therapies targeting DUX4-fl mRNA and/or protein and are useful to investigate certain conserved downstream FSHD-like pathophysiology. Overall, this model supports that DUX4 expression levels in skeletal muscle directly correlate with FSHD-like pathology by numerous metrics.

\section{Introduction}

Facioscapulohumeral muscular dystrophy (FSHD) afflicts females and males of all ages and an estimated 1:8,30022,000 people worldwide [1-4]. All forms of FSHD share a common pathogenic mechanism, increased somatic expression of the DUX4 (Double homeobox 4) retrogene caused by the loss of stable epigenetic repression of the chromosome 4q35.2 D4Z4 macrosatellite array [5-12]. Epigenetic dysregulation of the locus is caused by large deletions of the D4Z4 array on a single 4q allele, reducing it to 1-10 repeat units (RU) (classified as FSHD1) $[6,13,14]$, or by mutations in genes encoding repressive epigenetic regulators of the locus (classified as FSHD2) $[15,16]$. In addition, all forms of FSHD require a permissive DUX4 polyadenylation signal (PAS) in cis distal to a dysregulated chromosome 4q D4Z4 array [17]. Pathology ultimately results from the aberrant increase in stable somatic expression of the dysregulated DUX4 mRNA from the distal-most RU [5, 7, 9-12, 17-20].

The DUX4 gene encodes several mRNA isoforms generated by alternate 5 'splice site usage in the first exon [9]; however, only the DUX4-full length (DUX4-fl) mRNA is pathogenic when expressed in muscle $[9,17$, 21]. DUX4- $f l$ encodes a paired homeobox domain transcription factor (DUX4-FL) normally expressed in healthy human testis, pluripotent cells, and cleavagestage embryos, and the DUX4-mediated transcriptional program is key for zygotic genome activation, all of which supports an important role for DUX4-FL during early embryonic development [5, 9, 22-25]. Adult somatic cells from healthy individuals are typically devoid of detectable DUX4-fl expression $[9,17,18]$. However, individuals meeting the genetic criteria for FSHD express stable DUX4-fl mRNA and protein in their skeletal muscles, which aberrantly activate an embryonic gene expression profile $[9,17,18,26,27]$, ultimately leading to FSHD pathophysiology. Interestingly, low somatic expression of DUX4-fl mRNA per se is not necessarily pathogenic since expression can be detected in some rare cultures of myogenic cells and muscle biopsies from healthy and asymptomatic FSHD subjects, albeit at levels significantly lower than in equivalent cells and tissues from FSHD-affected subjects [10, 18, 19]. Epigenetic analysis of the pathogenic 4q D4Z4 RU shows that the stability of DUX4 epigenetic repression correlates with disease presentation among healthy, FSHD1-affected, and FSHD1-asymptomatic subjects [10]. Together, this data supports that the level of somatic DUX4-fl expression, which is inducible and affected by the epigenetic stability in the region, is the key determinant of disease onset and severity.

In addition to the complex genetic and epigenetic conditions that are required to develop clinical FSHD [11], the pathogenic mechanism is also unusual among neuromuscular diseases. While FSHD is an autosomal dominant gain-of-function disease, the pathogenic DUX4 gene is typically expressed in only a small fraction $(<1 \%)$ of cells, ultimately leading to debilitating muscle pathology over time $[9,18,28]$. This may account in part for the more common adult onset of clinical symptoms in FSHD patients [29, 30]. In addition, it appears that FSHD pathology is caused by sporadic bursts of increased DUX4-fl expression in differentiated myocytes, which are epigenetically suppressed in healthy and asymptomatic subjects [10, 21, 31, 32]. Since these cells are syncytial, the detrimental effects of aberrant DUX4FL expression may be found throughout an FSHD myofiber despite expression initially being restricted to a small percentage of myonuclei at any one time [28]. Regardless, DUX4-fl expression in FSHD myocytes and skeletal muscle, even when bursting, is still extremely rare, highly variable, and difficult to detect $[9,18,21]$.

Since DUX4-FL is a transcription factor not typically expressed in healthy muscle, its aberrant expression alters the mRNA profiles of numerous genes in myocytes [26, 33-35]. Many of these DUX4 target genes, including germline-specific genes, cleavage-stage genes, and immune system regulators, are not normally expressed in healthy myogenic cells $[24,26,33,34]$. In addition, DUX4-FL expression ultimately initiates a cascade of numerous potentially detrimental events including the disruption of proteostasis, nonsense-mediated decay, and mRNA splicing mechanisms [21, 36, 37], altered myogenesis [38-41], and induction of apoptosis [7, 21, 4244]. These DUX4-mediated changes, either alone or in combination, lead to progressive muscle cell death and ultimately pathology [20, 45]. Thus, the DUX4-fl mRNA and protein are prime targets for therapeutic intervention, and animal models for FSHD should be based on DUX4-fl expression in adult skeletal muscle. 
We have previously reported the generation of the FLExDUX4 (FLEXD) conditional DUX4-fl transgenic line of mice, which contains a DUX4 transgene engineered into the Rosa26 locus using the FLEx directional switch system [46, 47] to bypass the embryonic lethality from leaky embryonic expression of this transgene [48]. Upon Cre-mediated induction, the transgene recombines to express DUX4-fl under control of the Rosa26 gene promoter (Fig. 1a). Importantly, since many elements within DUX4 are prime targets for sequence-based therapies [49-52], the DUX4 transgene maintains the exon/intron structure of the endogenous human gene, including the $5^{\prime}$ untranslated region (UTR), the endogenous PAS, and the distal auxiliary elements (DAEs) that enhance DUX4 mRNA cleavage and polyadenylation events [5, 9, 5254]. Here, we show that the FLExD mouse model, when crossed with the skeletal muscle-specific and tamoxifen (TMX)-inducible ACTA1-Mer-cre-Mer mouse [55], produces a bi-transgenic model with chronic low levels of mosaic DUX4-fl expression in skeletal muscle and reproducibly recapitulating many aspects of FSHD pathophysiology. Further, when treated with TMX, this model can be induced to develop more severe pathology dependent upon the amount of TMX used, thus

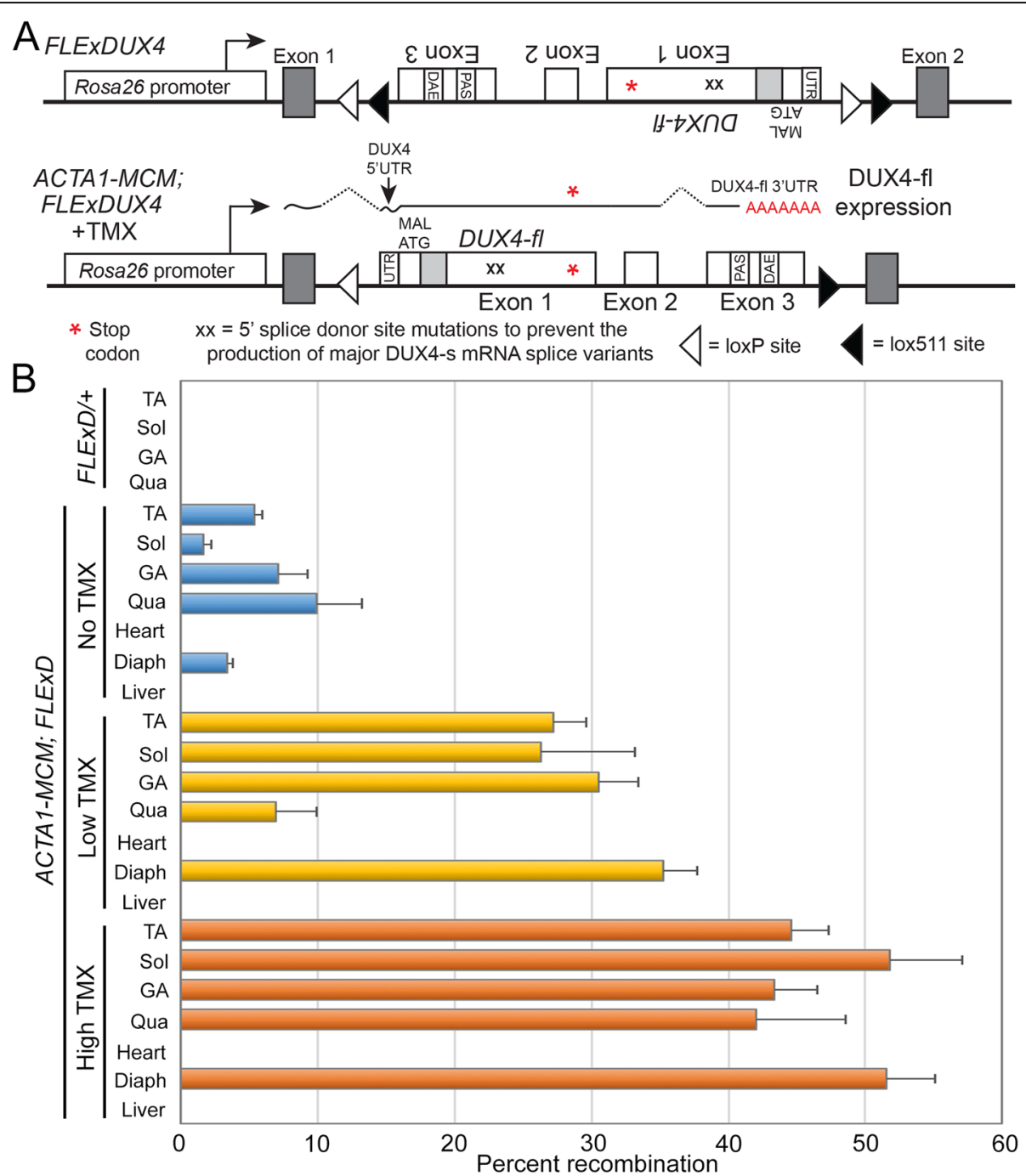

Fig. 1 Transgene map and FSHD-like model generation. a The synthesized FLEXDUX4 (FLEXD) transgene, flanked by heterologous lox sites (loxP and lox511), was inserted in the antisense orientation to the Rosa26 promoter and maintains the intron/exon structure and cis mRNA regulatory features, including the PAS and DAE, of the human chromosome 4q35 DUX4 gene. When crossed with ACTA1-MCM mice, the bi-transgenic offspring have the capacity for dosage-dependent, TMX-inducible unidirectional recombination of the transgene, resulting in DUX4 expression exclusively in skeletal muscle and transcribed from the Rosa26 promoter, processed, and terminated in exon 3 using the DUX4 PAS. b Genomic PCR indicating percent transgene recombination in different muscles from FLEXD/+ mice and bi-transgenic ACTA7-MCM;FLEXD mice with no TMX or 3 days after a single IP injection of $5 \mathrm{mg} / \mathrm{kg}$ TMX (low), or two IP injections of $10 \mathrm{mg} / \mathrm{kg}$ TMX (high). TA, tibialis anterior; Sol, soleus; GA, gastrocnemius; Qua, quadriceps; Diaph, diaphragm 
providing several suitable models of FSHD severity for therapeutic interventions targeting DUX4-fl mRNA, protein, and certain downstream pathways and pathology.

\section{Methods}

\section{Mouse husbandry}

All mice for this study were bred and maintained in a specific-pathogen-free barrier animal facility at the University of Nevada, Reno (UNR), School of Medicine. Staff were required to wear disposable personal protective clothing including hair bonnets, coveralls, gloves, and shoe covers and use the high-level surface disinfectant Clidox-S (Pharmacal Research Laboratories, Inc., Naugatuck, CT). Mice were housed on autoclaved corncob bedding (Teklad 7092, Envigo RMS, Indianapolis, IN) in solid-bottom and individually ventilated polysulfone cages (Tecniplast USA, West Chester, PA) with the air handler set to 70 air changes per hour. Reverse-osmosis purified water and irradiated maintenance diet (Teklad 2919) was provided ad libitum. Structural enrichment of rodent cages included Alpha-twist paper nesting material (Shepherd Specialty Papers, Watertown, TN) and high-temperature polycarbonate shelters (Bio-Serv, Flemington, NJ). The animal room was maintained at $70^{\circ} \mathrm{F}$ in a 12:12-h light:dark cycle and 10-12 air changes per hour with $40 \%$ relative humidity. Fresh cages were provided every 14 days using a HEPA-filtered downdraft laminar airflow cage changing station. The soiled-bedding sentinel mouse health surveillance system verified absence of all murine pathogens for all periods during these studies, including Clostridium piliforme, Mycoplasma pulmonis, CAR bacillus, Ectromelia virus, EDIM virus, lymphocytic choriomeningitis virus, mouse adenoviruses 1 and 2, mouse cytomegalovirus, mouse hepatitis virus, murine norovirus, mouse parvoviruses, polyomavirus, reovirus type 3 , Sendai virus, Theiler's murine encephalomyelitis virus, Encephalitozoon cuniculi, Helicobacter spp., Pasteurella pneumotropica, the pinworms Aspiculuris tetraptera and Syphacia spp., and the fur mites Myobia spp., Myocoptes spp., and Radfordia spp. All procedures were approved by the UNR Institutional Animal Care and Use Committee. The UNR animal care and use programs are fully accredited by AAALAC, International.

\section{Transgenic mice}

The ACTA1-MCM Cre driver line refers to B6.Cg-

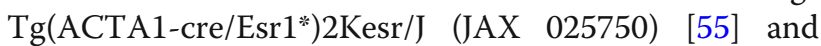
Rosa26 ${ }^{\text {NZG }}$ refers to FVB.Cg-Gt(ROSA)26Sor< tm1(CAG-lacZ,-EGFP)Glh>/J (JAX 012429) [56], both purchased from Jackson Labs (Bangor, Maine). FLEXDUX4 (FLEXD) mice were generated and characterized by the PL Jones lab [48] and are available from Jackson Labs (JAX 028710). Mice were genotyped as described [48].

\section{Tamoxifen (TMX) injections}

Tamoxifen free base (Sigma T5648) was dissolved in $100 \%$ ethanol $(200 \mathrm{mg} / \mathrm{ml})$ at $55^{\circ} \mathrm{C}$ and added to prewarmed clean corn oil (ThermoFisher S25271) to make $20 \mathrm{mg} / \mathrm{ml}$ frozen stocks. Stock TMX aliquots were warmed to $37^{\circ} \mathrm{C}$, diluted with pre-warmed sterile corn oil either 10- or 20-fold just prior to use, and administered to mice by intraperitoneal (IP) injection at a final concentration of 5 or $10 \mathrm{mg} / \mathrm{kg}$. For the moderate model, ACTA1-MCM; FLEXD bi-transgenic animals were injected once with $5 \mathrm{mg} / \mathrm{kg}$ TMX. For the severe model, ACTA1-MCM; FLEXD bi-transgenic mice were injected on two consecutive days with $10 \mathrm{mg} / \mathrm{kg}$ TMX.

\section{X-Gal staining for evaluating TMX dosing}

Male ACTA1-MCM mice were crossed with female Rosa26 ${ }^{N Z G}$ mice to assess induction of Cre-mediated recombination using our TMX dosage regimens. Control or bi-transgenic mice $(n=3)$ were treated with TMX, as above. Whole gastrocnemius muscles were fixed in LacZ fixative (0.2\% glutaraldehyde, $5 \mathrm{mM}$ EGTA, $100 \mathrm{mM} \mathrm{MgCl} 2$ in PBS pH 7.4) at $4{ }^{\circ} \mathrm{C}$ for $4 \mathrm{~h}$, cryopreserved in cold $30 \%$ sucrose/PBS at $4{ }^{\circ} \mathrm{C}$ overnight, then frozen in O.C.T. for sectioning. Cryosections $(8 \mu \mathrm{m})$ were fixed with $4 \%$ paraformaldehyde (PFA)/PBS and then stained with X-Gal staining solution $(1 \times \mathrm{PBS}$ with $2 \mathrm{mM} \mathrm{MgCl}, 5 \mathrm{mM}$ potassium ferricyanide, $5 \mathrm{mM}$ potassium ferrocyanide, $0.01 \%$ Nonidet P40, $0.1 \%$ sodium deoxycholate, $1 \mathrm{mg} / \mathrm{mL} \mathrm{X-Gal)} \mathrm{for} 50 \mathrm{~min}$. Stained sections ( $n=10 /$ muscle analyzed) were post-fixed in buffered formalin at $4{ }^{\circ} \mathrm{C}$ for $5 \mathrm{~min}$, rinsed three times with PBS, and then deionized water before mounting. Images were captured using an Olympus CX41 microscope with PixeLINK camera under bright field.

\section{Transgene recombination assay}

The direction of floxed DUX4 transgene in FLExD mouse will be recombined to sense direction by Cre recombinase. The non-recombined transgene (NR) was detected by PCR of 100-ng genomic DNA using primers; Forward: 5' CAATACCTTTCTGGGAGTTCTCTGCTGC-3' and Reverse: 5' - CTCGTGTAGACAGAGCCTAGACAATT TGTTG-3', and recombined transgene (R) was detected using different reverse primer, 5 ' - AGGCTCGCAGGGCC TCGCTT-3'. PCR products were visualized by ethidium bromide staining after agarose gel electrophoresis, and the intensities of PCR products were quantified using volume tool of BioRad Image Lab software ver.4, global subtraction method. Recombination rate was calculated as follows $\%=[R /(\mathrm{NR}+R)] \times 100$.

\section{Gene expression analysis by RT-PCR}

Specific mRNA expression was determined for each severity model using 3-4 mice per model. Total RNA was extracted from dissected mouse muscles homogenized 
in 10 volumes of TRIzol (ThermoFisher) using the TissueLyser LT (Qiagen), as per manufacturer's instructions followed by on-column DNaseI treatment and clean-up using the RNeasy mini kit (Qiagen). Quantitative DUX4$f l$ mRNA expression was analyzed using nested qRTPCR, as described [48, 57]. Expression of DUX4 target genes was analyzed by qPCR using 5 to $10 \mathrm{ng} \mathrm{cDNA}$, as described [33, 48]. All oligonucleotide primer sequences for DUX4-fl, downstream targets, and $18 S$ rRNA are previously reported [31]. Expression of Myostatin mRNA was analyzed by qRT-PCR using primers $5{ }^{\prime}$-AGTGGA TCTAAATGAGGGCAGT-3' (forward) and 5'GTTTCCAGGCGCAGCTTAC-3' (reverse). Significance was calculated using the two-tailed $t$ test.

\section{Histology}

Freshly dissected muscles were kept moist, coated with O.C.T. compound, snap-frozen in liquid nitrogen-cooled isopentane, and stored at $-80{ }^{\circ} \mathrm{C}$ until sectioning. Cryosections $(12 \mu \mathrm{m})$ were mounted on slides and air-dried before staining or storage. Sections were used for hematoxylin and eosin $(\mathrm{H} \& \mathrm{E})$ staining [48] or picrosirius red staining. All histological analyses were done with the identity of the sample blinded to the person performing the assessment.

\section{Centralized nuclei}

H\&E staining was performed as described [48]. A series of micrographs from each muscle section were captured using a $\times 20$ objective on a Leica DM2000 and reconstituted to form a whole muscle cross section using LAS 4.12 software (Leica Microsystems, Inc.). Muscle sections taken from similar points in the soleus or tibialis anterior muscles were used across the models. The number of muscle fibers with or without internally located nuclei were counted using Image J software.

\section{Picrosirius red (SR) staining}

SR staining was performed as described [58]. Cryosections $(12 \mu \mathrm{m})$ cut mid-belly of the tibialis anterior muscle were fixed with $4 \%$ PFA/PBS, pH 7.4 for $10 \mathrm{~min}$, rinsed with $\mathrm{dH}_{2} \mathrm{O}$, and dehydrated with a series of $1 \mathrm{~min}$ ethanol washes $(70 \%, 95 \%, 100 \%)$, and air-dried. Sections were then stained for $1 \mathrm{~h}$ in SR solution $(0.1 \%$ direct red $80,1.3 \%$ saturated picric acid), and washed three times with $\mathrm{dH}_{2} \mathrm{O}$. Stained sections were dehydrated with a series of $1 \mathrm{~min}$ ethanol washes $(70 \%, 95 \%$, and $100 \%)$, cleared with xylene for $5 \mathrm{~min}$, and mounted. A series of micrographs from each muscle section were captured using a $\times 10$ objective on a Leica DM2000 and reconstituted to form a whole muscle cross section using LAS 4.12 software (Leica Microsystems, Inc.). Whole cross section images ( $n=2$ per muscle) were divided into 3-5 sections and processed with MATLAB (Mathworks) to determine the number of pixels stained red and the total number of pixels stained. Muscles from 3-4 mice for each treatment were analyzed. Significance was calculated by one-way ANOVA using Prism 7 (Graphpad).

\section{Immunofluorescence (IF)}

The 10- $\mu \mathrm{m}$ cryosections of muscle tissues were fixed with $4 \%$ PFA/PBS on ice for $10 \mathrm{~min}$, permeabilized with $0.25 \%$ TritonX-100/PBS for $10 \mathrm{~min}$, incubated with blocking solution (5\% normal goat serum, 2\% BSA, $0.01 \%$ TritonX-100/PBS) for $30 \mathrm{~min}$, and then incubated with primary antibody at $4{ }^{\circ} \mathrm{C}$ overnight. The following day, sections were incubated with secondary antibody at room temperature for $40 \mathrm{~min}$, then mounted in ProLong Gold with DAPI for nuclear staining. DUX4 was detected using E5-5 antibody (Abcam ab124699) diluted 1: 200. Embryonic fast myosin heavy chain was detected using the F1.652 monoclonal antibody, developed by the Baxter Lab for Stem Cell Biology, Stanford University, and obtained from the Developmental Studies Hybridoma Bank, created by the NICHD of the NIH and maintained at The University of Iowa, Department of Biology, Iowa City, IA 52242. Dystrophin was detected using an anti-dystrophin rabbit polyclonal antibody (Abcam, ab15277). Immunofluorescent images were captured using the Leica DMi8, DFC365 FX camera, and LAS X software (Leica Microsystems Inc.). Three nonconsecutive sections from each muscle of 3-4 mice per group were analyzed.

\section{Apoptosis assay}

Apoptotic events were analyzed by TUNEL (terminal deoxynucleotide transferase dUTP nick end labeling) staining using the In Situ Cell Death Fluorescein Kit (Roche/SIGMA 11684795910). The 10- $\mu \mathrm{m}$ cryosections of TA muscles were mounted on slides and fixed with $4 \%$ paraformaldehyde for $20 \mathrm{~min}$. Staining was performed as per manufacturer's instructions. Three nonconsecutive sections from each muscle of 3-4 mice per group were analyzed.

\section{Treadmill exhaustion test}

All treadmill tests were performed with an Exer3/6 treadmill and shock detection system (Columbus Instruments) in the mouse mode with electric shocking grid. All mice were acclimated to the apparatus before running by placing them on an unmoving treadmill for 5 min, then at a speed of $5 \mathrm{~m} / \mathrm{min}$ for $5 \mathrm{~min}$ at $0^{\circ}$ incline with electric shock grid on. Mice were rested for 2 days before the first test. The exhaustion test was established for these FSHD-like model mice after several modifications of the Treat-NMD protocol DMD_M.2.1.003. The test was performed using a $7^{\circ}$ incline and an initial speed of $5 \mathrm{~m} / \mathrm{min}$ with speed increasing by $0.5 \mathrm{~m}$ every minute. 
Mice were run until they were unable to maintain a speed to remain off the shock grid for more than $5 \mathrm{sec}$ (time of fatigue) or a maximum of $20 \mathrm{~min}$ (approximate maximum speed is $15 \mathrm{~m} / \mathrm{min}$ and maximum distance is $200 \mathrm{~m}$ ). This testing was performed at least three times per mouse with at least 2 days of rest in between tests. There were 3-4 mice analyzed per group. Significance was calculated by two-way ANOVA using Prism 7 (Graphpad).

\section{Ex vivo muscle contractile properties}

EDL muscles ( $\mathrm{n}$ indicated in figure legends) were excised from deeply anesthetized mice with $3 \%$ isoflurane, hung from a computer-controlled servomotor (300B, Aurora Scientific, Inc), and mounted in a heated $\left(30^{\circ} \mathrm{C}\right)$ oxygenated tissue bath containing a physiologic salt solution as described [59, 60]. Experiments were performed, and data were analyzed using DMA software (Aurora Scientific, Inc) and Prism 7 (Graphpad), as previously described (Treat-NMD SOP, DMD_M.1.2.002, and [60]). Significance for twitch and tetanus was calculated by one-way ANOVA, and for the force frequency analysis, it was calculated by two-way ANOVA using Prism 7 (GraphPad).

\section{RNA-seq}

RNA-seq was performed by Genewiz LLC (South Plainfield, NJ). Total RNA $(5 \mu \mathrm{g})$ was isolated from gastrocnemius muscles of 13-week-old mice, 3 mice per group (ACTA1-MCM, FLEXD, ACTA1-MCM;FLEXD mild/no TMX, ACTA1-MCM;FLEXD moderate TMX, and ACTA1-MCM;FLEXD severe TMX), as described above. The mRNAs were purified using poly(A) selection and then fragmented. First-strand cDNA synthesis used random priming followed by second-strand synthesis. The resulting double-strand cDNA was end repaired, phosphorylated, and A-tailed. Adapters were ligated and PCR amplification was performed. The library was sequenced using the Illumina HiSeq2500platform in a $1 \times 50$ base pair single-read configuration in Rapid Run mode, with a total of at least 120 million reads per lane. Sequence reads were trimmed to remove adapter sequences and poor quality nucleotides (error rate $<0.05$ ) at the ends. Sequence reads shorter than 50 nucleotides were discarded.

\section{Differential RNA-seq expression and gene ontology (GO) analysis}

Data sources

RNA-seq reads for C2C12 expressing DUX4-fl or control were downloaded from the Gene Expression Omnibus (accession number GSE87282) [25].

\section{Genome annotation, read mapping, and gene expression estimation}

Human (hg19) and mouse (mm10) genome annotations were created by merging the UCSC knownGene [61], Ensembl 71 [62], and MISO v2.0 [63] annotations. Sequence reads were mapped to these annotations as previously described [64]. In brief, RSEM v1.2.4 [65] was modified to call Bowtie [66] with the option "-v 2" and then used to map all reads to the merged genome annotation. Remaining unaligned reads were then mapped to the genome and a database of potential splice junctions with TopHat v2.0.8b [67]. All gene expression estimates were normalized using the trimmed mean of $M$ values (TMM) method [68].

Differentially expressed genes (Table S1 and GEO accession number GSE122562) in DUX4-induced versus control experiments were defined at a threshold of 1.4-fold and 2-fold change and Bayes factor $\geq 10$ (computed with Wagenmakers's framework [69]), as observed in all possible pair-wise comparisons of experimental replicates. A gene that was differentially expressed was a gene that was significantly upregulated or downregulated in all 3 replicate comparisons. Genes listed in Table S1 were at 1.4fold. Gene ontology (GO) terms that were enriched among genes that exhibited increased or decreased expression in DUX4-induced versus control samples were identified with the GOseq method [70], with a falsediscovery rate threshold of 0.01 . GO superterms (Table S4) are all terms that are descendent of GO terms containing the following key terms, respectively:

Cell cycle: cell cycle, mitosis, mitotic, chromosome segregation, cell division, nuclear division, proliferation, chromosome condensation, kinetochore, spindle, cyclin

Apoptosis: apoptosis, cell death, apoptotic, cell killing

Muscle: muscle, sarco, myofibril

Immune: immune, chemokine, interferon, wound, virus, cytokine, cytokine-, leukocyte, interleukin, Tolllike, toll-like, bacteri, inflamma, defense, immunological, immunoglobulin receptor, $\mathrm{MHC}$, immunoglobulin, viral

Differentially expressed genes from the comparison of 9 control and 9 FSHD1 muscle biopsies [26] were defined as genes that were consistently differentially expressed at a threshold of Bayes factor $\geq 10$ (computed with Wagenmakers's framework [69]) in more than 50 out of 81 possible pair-wise comparisons between control and FSHD1 muscles. The intersection of these genes with orthologous differentially expressed mouse genes from DUX4-induced vs control experiments are summarized in Table S3.

\section{Data analysis and visualization}

All data analysis was performed in the $\mathrm{R}$ programming environment and relied on Bioconductor [71], dplyr [72], and ggplot2 [73]. Venn diagrams were plotted using 
the venneuler package. For significance, fold change thresholds of 1.4-fold (i.e., log2 fold change of 0.5) or 2fold (i.e., $\log 2$ fold-change of 1), depending on the Venn diagram.

\section{Alternative splicing analysis}

The MISO computational method [63] was used to characterize skipped exon (SE) and retained intron (RI) alternative splicing events for 12 RNA-seq samples from the control, FLExD, moderate, and severe models (Table 3 and Table S6). MISO (version 0.5.3) was executed with mapping results produced with TopHat, using the following configuration: --read-len:51, min_event_reads = 20 , burn_in $=500$, lag $=10$, num_iters $=5000$, and num_chains $=6$.

\section{Results}

The FLExDUX4 (FLExD) line of transgenic mice was developed and first characterized by the PL Jones lab while at the University of Massachusetts Medical School (UMMS), was deposited into Jackson Labs for distribution (\#028710), and is described elsewhere [48]. The original description of the model reported alopecia, rectal prolapse, and soft stools as commonplace in the heterozygous $F L E x D /+$ transgenic mouse and more even more pronounced in the homozygous FLExD/FLExD line (Figure S1 and Figs. 2 and S4 in ref [48]), indicating they were linked to the low leaky levels of DUX4-fl expression that were higher in the transgene homozygote. In addition, these gastrointestinal (GI) phenotypes suggested there may be some gut inflammation exacerbated by low levels of leaky DUX4 expression. This GI phenotype may not be acceptable to veterinary staffs at some institutions and prevent import and use. However, in 2017, the PL Jones lab moved to the University of Nevada, Reno School of Medicine (UNR Med), and relocated the FLExD mouse colony used in this current study. In order to enter the UNR Med barrier facility, mice from UMMS were analyzed for undesirable bacteria and viruses. In addition to being found positive for murine norovirus (MNV), analysis of the gut flora from the UMMS housed mice revealed the presence of Pasteurella pneumotropica and Helicobacter mastomyrinus, which necessitated re-derivation of the line to allow import. Helicobacter species (ssp) have been known to cause rectal prolapse and diarrhea in some immune

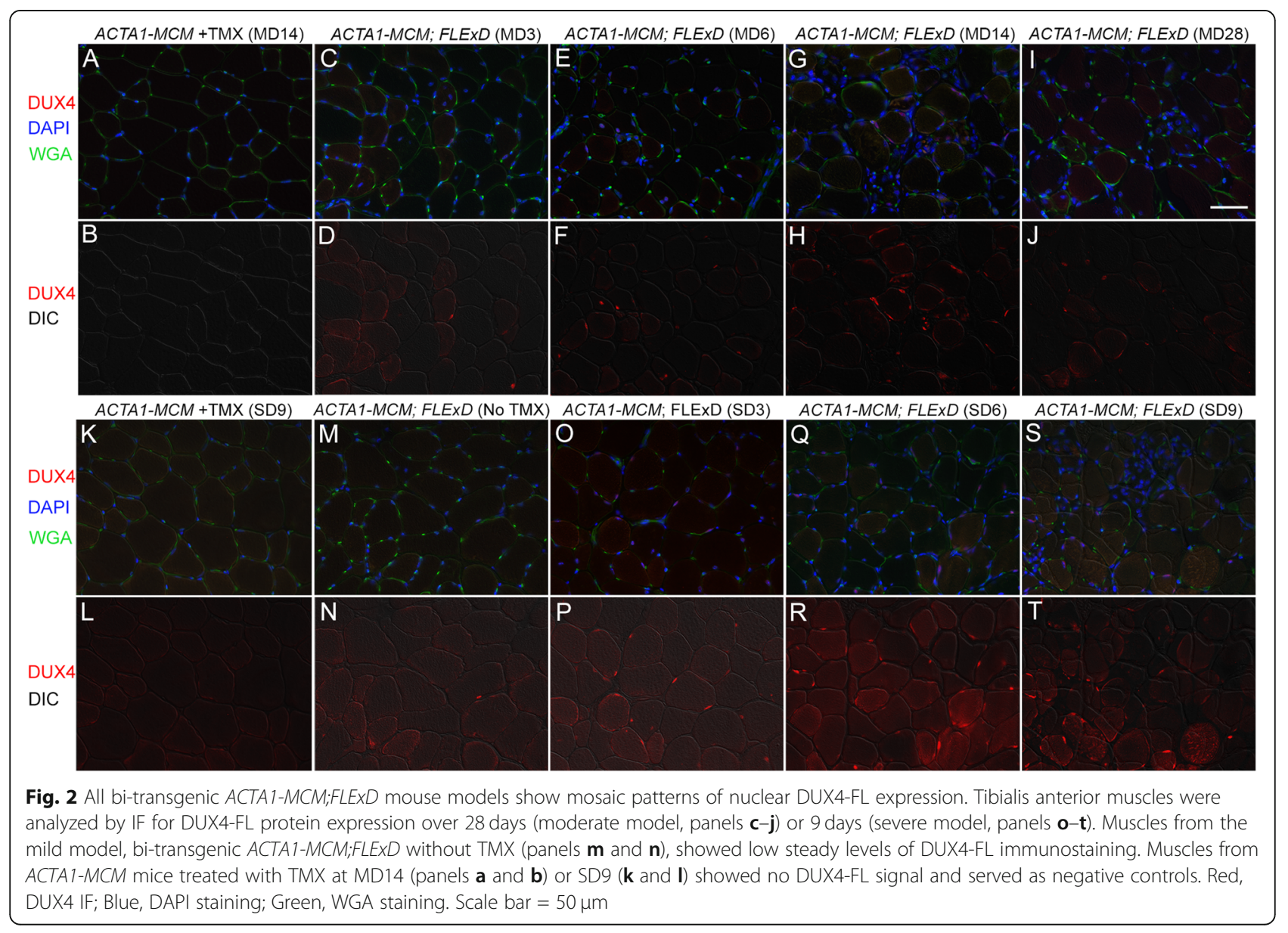


deficient or otherwise susceptible animals [74]. After rederivation, the UNR Med housed mice tested negative for MNV, Helicobacter ssp, and Pasteurella pneumotropica biotypes Jawetz and Heyl. Interestingly, the prior alopecia phenotype was much less pronounced in the UNR Med housed mice and the soft stools and rectal prolapse have not been seen in the UNR Med FLExD mouse colony over 3 years (Figure S1), supporting these were a result of different gut microbiomes. This is a good illustration of potential overlooked sources of variability between labs when using the same transgenic mouse models of human disease [75, 76]. Investigators should be aware of these adverse effects, which may also impact experimental outcomes, when using the FLExD mouse model and similarly that they can potentially be overcome by mouse facility conditions.

\section{Generation of mice with mosaic DUX4-fl expression in skeletal muscles}

FSHD is caused by mosaic expression of DUX4- $f l$ mRNA and its encoded protein from the normally silent $D U X 4$ gene in a small fraction of differentiated adult skeletal myocytes $[9,18,21]$. Previously we generated a conditional DUX4-fl expressing transgenic mouse, FLExD, and showed that high expression of DUX4-fl in skeletal muscle can produce a very severe myopathy with some FSHD-like pathology [48]. However, high levels of $D U X 4-f l$ expression in many skeletal myonuclei does not recapitulate the mosaic rare myonuclear expression of DUXY-fl found in FSHD subjects and preclinical testing for different candidate FSHD therapeutics targeting DUX4-fl mRNA, and protein expression will likely require different criteria, such as lesser degrees and slower progression of pathophysiology, dependent upon the approach. To address this issue, we generated and characterized a highly reproducible series of phenotypic FSHDlike transgenic mouse models varying in severity and pathogenic progression based on differing levels of mosaic expression of the pathogenic DUX4-fl mRNA isoform of human DUX4 in adult murine skeletal muscle. We identified the tamoxifen (TMX) inducible and skeletal muscle-specific Cre expressing transgenic mice, ACTA1-MerCreMer (or ACTA1-MCM) [55] as a strong candidate for the generation of the desired phenotypes. To test if these could be used to generate mosaic expression in skeletal muscles and to optimize TMX dosing, the ACTA1-MCM mice were crossed with $R 26^{N Z G}$ Cre reporter mice [56] that produce readily detectable nuclear $ß$-galactosidase ( $\mathrm{n} L a c Z$ ) expression in all cells where Cre is functional in the nucleus (Figure S2). Two dosing regimens of TMX were tested in the ACTA1$M C M$; $R 26^{N Z G}$ bi-transgenic offspring, a single low-dose $(5 \mathrm{mg} / \mathrm{kg})$ intraperitoneal (IP) injection and two IP injections on consecutive days of a higher dose $(10 \mathrm{mg} / \mathrm{kg})$.
Expression of the $\mathrm{nLacZ}$ reporter gene was visualized by $\mathrm{X}-\mathrm{Gal}$ staining [77] in the gastrocnemius muscles isolated 2 weeks after TMX injection. The results indicated that both dosing regimens produced mosaic patterns of Cre-mediated recombination in skeletal muscle, with the high TMX dose producing $\sim 1.5 \times$ more $\mathrm{X}-\mathrm{Gal}$ stained nuclei than the low-dose (Figures S2 and S3). There was no significant difference in transgene recombination between male and female mice (Figure S4). Surprisingly, in the absence of TMX the ACTA1-MCM;R26 $6^{N Z G}$ mice also showed transgene recombination, although only in a very small fraction of skeletal muscle nuclei (Figure S2C). Interestingly, this low-level recombination and nLacZ expression was not uniform across all nuclei; rather, it also showed a mosaic pattern of recombination ( $\sim$ one third the number of recombined nuclei induced by the low TMX dose, Figure S3C compared with S3D). Since there was no indication of recombination in the $R 26^{N Z G}$ single transgenic animals treated with TMX (Figure S2B), we interpret this result as indicating a low level of MerCreMer protein leaking into the nucleus in the absence of TMX, either at a level that only occasionally leads to recombination or the protein is only sporadically leaky into a few nuclei. Regardless, this suggested that bi-transgenic animals generated with the ACTA1$M C M$ line may be useful for generating very low mosaic expression of a transgene in the absence of TMX induction. Overall, we concluded that the ACTA1-MCM line of mice was suitable for generating a range of mosaic transgene expression models.

Generating FSHD-like model mice with differing levels of pathophysiology required adjusting the level of mosaicism with respect to DUX4-fl expression. Therefore, ACTA1-MCM mice were crossed with FLEXD mice [48] (Fig. 1a), and 13-14-week-old ACTA1-MCM;FLExD bitransgenic mice were treated with the above TMX dosing regimens to induce differing levels of mosaic transgene recombination. Genomic DNA was isolated 3 days post-injection (DPI) of TMX and assayed for transgene recombination by genomic PCR (Fig. 1b). The FLExD hemizygous mice showed no transgene recombination in the absence of Cre, and the bi-transgenic animals showed variable low levels $(2-10 \%)$ of transgene recombination in skeletal muscles, but not in the heart or liver, in the absence of TMX, due to the abovementioned sporadic leaky nuclear Cre activity in ACTA1-MCM mice. When injected with TMX to induce Cre nuclear activity and stimulate transgene recombination in skeletal muscles, the bi-transgenic mice showed increased recombination $(8-30 \%)$ in response to the low TMX dose and an even higher level of recombination (38$55 \%$ ) in response to the high TMX dose. Surprisingly, in all three bi-transgenic models (no, low, and high TMX), there were muscle-specific differences in the transgene 
recombination rate; however, these differences were consistent between the TMX treated lines (Fig. 1b). For example, quadriceps muscles showed the lowest recombination in both TMX-induced models, followed by the tibialis anterior (TA) and gastrocnemius muscles with intermediate levels, while the diaphragm and soleus showed the highest recombination levels. As expected when using the ACTA1-MCM driver line, the heart and liver showed no transgene recombination in any of the bi-transgenic animals. Since this assay measures transgene recombination of a single copy transgene per nucleus, the results showing less than $100 \%$ recombination represent mosaic recombination which should translate into the desired mosaic DUX4-fl transgene expression. Importantly, variable muscle-specific recombination efficiencies were not significantly different between male and female mice (Fig. S4). We conclude that we have identified three conditions that reproducibly produce differing levels of mosaic transgene recombination, which we will refer to as mild, moderate, and severe (Table 1 ), based on the subsequent characterizations described below. Importantly for future studies, we show that different skeletal muscles show different levels of recombination in response to these TMX treatments.

To assess if the variable rates of transgene recombination in each model translated similarly to variable levels of protein expression at the single nucleus level, muscle tissues were analyzed by immunofluorescence (IF) using an anti-DUX4-FL antibody. Mosaic patterns of nuclear DUX4-FL expression were readily detected in cross sections of TA muscle from all three models (Fig. 2). The bitransgenic ACTA1-MCM;FLEXD mild model showed few DUX4-FL-positive nuclei in the absence of TMX (Fig. 2m and $\mathrm{n}$ ), consistent with a very low level of transgene recombination (Fig. 1b). However, since DUX4-FL is cytotoxic and it is not known how long DUX4-FL expressing cells may remain in the muscles, an IF time course study was performed for the TMX-injected mice and the DUX4-FL protein-positive myonuclei were quantified (Figs. 2 and S5). The low-dose mice, which appeared to be moderately affected phenotypically over time and will be

Table 1 FSHD-like mouse severity models

\begin{tabular}{|c|c|c|c|c|}
\hline Genotype & TMX & $\begin{array}{l}\text { Transgene } \\
\text { recombination }\end{array}$ & $\begin{array}{l}\text { DUX4-fl } \\
\text { expression }\end{array}$ & Phenotype \\
\hline $\begin{array}{l}\text { ACTA1-MCM/ } \\
+\end{array}$ & $\begin{array}{l}5 \mathrm{mg} / \mathrm{kg} \times \\
1 \mathrm{IP}\end{array}$ & $\mathrm{NA}$ & No & $\begin{array}{l}\text { Control } \\
\text { moderate }\end{array}$ \\
\hline $\begin{array}{l}\text { ACTA1-MCM } \\
+\end{array}$ & $\begin{array}{l}10 \mathrm{mg} / \mathrm{kg} \\
\times 2 \mathbb{P}\end{array}$ & NA & No & $\begin{array}{l}\text { Control } \\
\text { Severe }\end{array}$ \\
\hline $\begin{array}{l}\text { ACTA1-MCM; } \\
\text { FLEXD/+ }\end{array}$ & None & $2-10 \%$ & Yes & Mild \\
\hline $\begin{array}{l}\text { ACTA1-MCM; } \\
\text { FLEXD/+ }\end{array}$ & $\begin{array}{l}5 \mathrm{mg} / \mathrm{kg} \times \\
1 \mathbb{P}\end{array}$ & $7-28 \%$ & Yes & Moderate \\
\hline $\begin{array}{l}\text { ACTA1-MCM; } \\
\text { FLEXD/+ }\end{array}$ & $\begin{array}{l}10 \mathrm{mg} / \mathrm{kg} \\
\times 2 \mathbb{P}\end{array}$ & $38-55 \%$ & Yes & Severe \\
\hline
\end{tabular}

referred to as the moderate FSHD-like model (Table 1, discussed in detail below), were assayed over 28 DPI. DUX4-FL expression appeared by 3 DPI (moderate day 3, or MD3), peaking at MD14, and then was greatly reduced by MD28, likely due to the death of DUX4-positive cells (Fig. 2a-j). Mice injected with the high-dose TMX regimen were so severely affected by 9 DPI that they had to be sacrificed and could not be assessed further. These mice, which will be referred to as the severe FSHD-like model, similarly showed DUX4-FL expression by 3 days after the first injection (severe day 3, or SD3) and peak DUX4-FL expression at SD6. DUX4-FL expressing myonuclei had decreased in number by SD9, likely due to massive cell death. Overall, the mild FSHD-like model exhibited very low numbers of DUX4-FL-positive myonuclei, with the moderate model exhibiting a significant increase ( $>5$-fold) in DUX4-FL-positive myonuclei, and the severe model had the highest numbers of DUX4-FLpositive myonuclei, with a $>10$-fold increase compared with the mild model (Figure S5). DUX4-FL protein was not detectable in the heart or skeletal muscles from the non-recombined FLEXD mice or ACTA1-MCM controls. Thus, each model consistently displays mosaic nuclear DUX4-FL protein expression patterns (Fig. 2) and provides an indication of the relative abundance of DUX4FL-expressing nuclei in bi-transgenic animals and in response to two different TMX treatments.

In order to quantitate the changes in gene expression for each severity model, qRT-PCR was used to measure overall DUX4- $f l$ mRNA levels (Fig. 3a). However, we have previously shown that this assay is a poor measure of DUX4- $f l$ transgene expression using FLEXD mouse models [48], likely due to DUX4induced cell death, and DUX4- $f l$ mRNA is even difficult to detect in muscle biopsies from FSHD-affected subjects [18]. Since DUX4-FL functions as a transcriptional activator in both human and mouse cells [33, 78], expression of DUX4-FL direct target genes has proven to be a more accurate indicator of DUX4FL expression levels in both species [26, 34, 35, 48]. Therefore, in addition to DUX4- $f l$ mRNA, the mRNA levels of two mouse homologs of DUX4-FL direct target genes, Wfdc3 and Trim36 [48, 78], were also assayed (Fig. 3b and c). Detectable DUX4- $f l$ mRNA levels were extremely low in gastrocnemius muscles from all models (Fig. 3a), consistent with previous studies [48]. Interestingly, there were no significant changes detected in DUX4-fl mRNA levels between the mild, moderate, and severe models 9 days after TMX treatments, a time point with prominent differences in DUX4-FL protein expression (Figs. 2 and S5). In contrast, both DUX4-FL target genes assayed showed significant induction in all models compared with the $F L E x D /+$ mice, indicating the presence of 
A

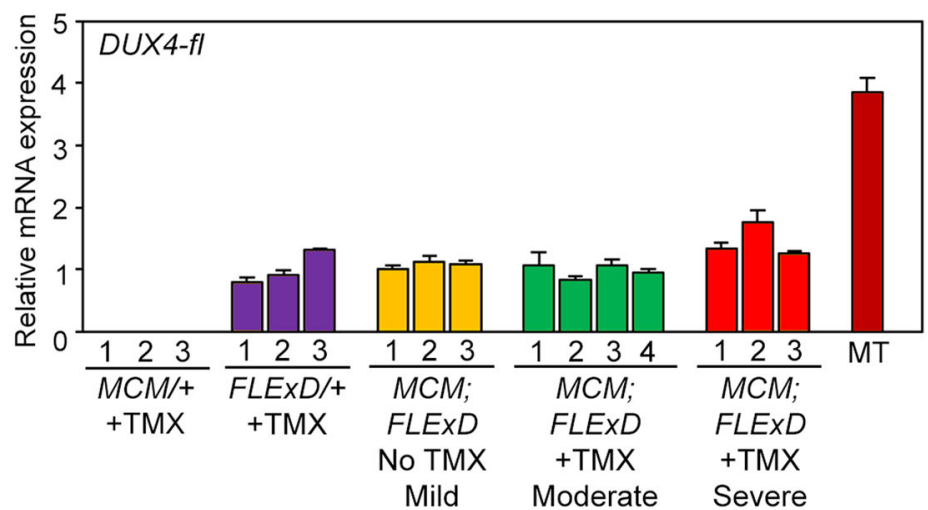

$\mathrm{B}$

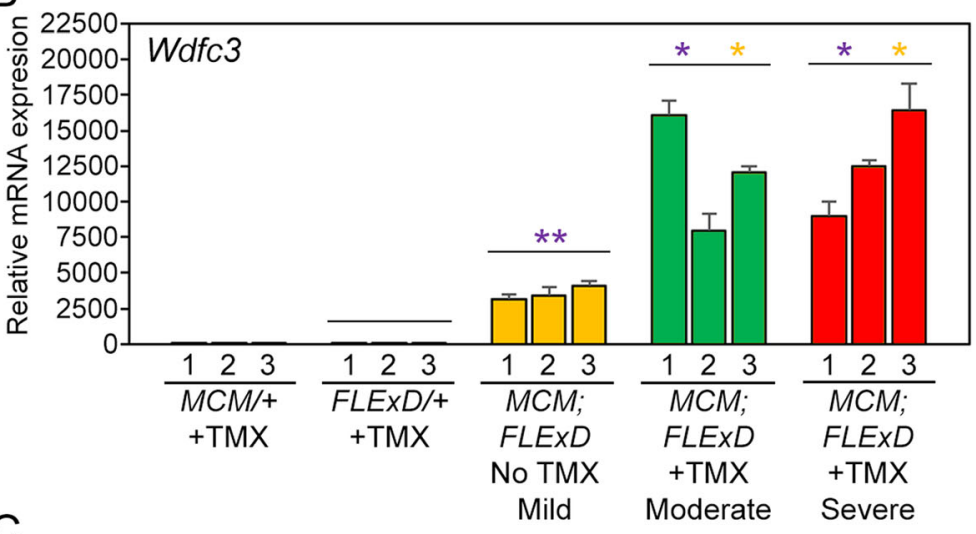

C

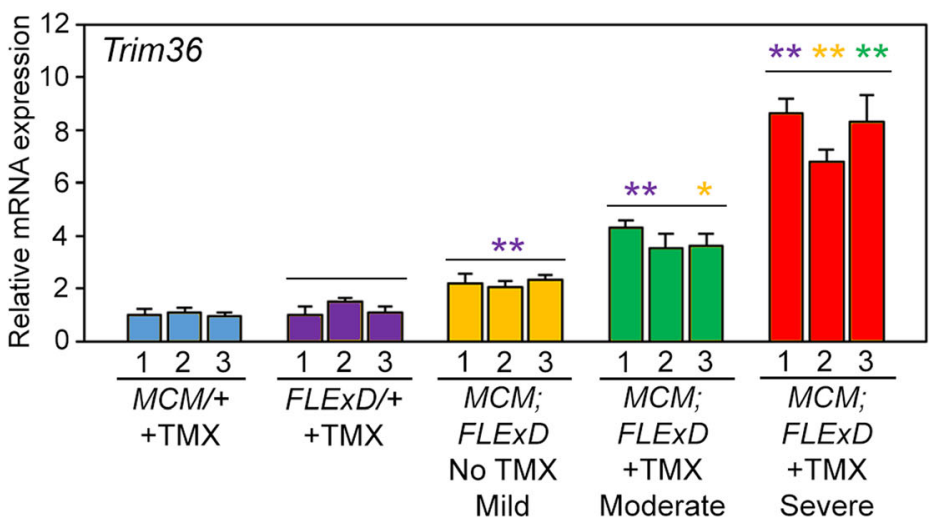

Fig. 3 DUX4-FL target genes, but not DUX4-fl mRNA, show TMX dose-dependent increased expression. Gastrocnemius muscles from 13-14week-old female mice isolated 9 days after TMX administration were assayed for gene expression levels by qRT-PCR. a Levels of DUX4-fl mRNA are not significantly different between the FLEXD mice and the three bi-transgenic models. However, mRNA expression of $\mathbf{b}$ Wdfc 3 and $\mathbf{c}$ Trim36 are increased significantly in all bi-transgenic models compared with FLEXD. Both Wdfc3 and Trim36 are significantly increased by moderate and severe TMX induction compared with no TMX. Trim36 mRNA levels are significantly increased in the severe compared to moderate models. All expression is normalized to RpL37 expression. MT, equivalent level of CDNA from 17Abic FSHD1 myotubes [18]. Data are mean \pm S.D. with significance calculated using Welch's $t$ test, ${ }^{*} p<0.05,{ }^{* *} p<0.01$

DUX4-FL protein. $W d f c 3$ and Trim36 mRNA levels are each significantly increased in muscles from the moderate and severe models compared with the mild model, and Trim36 mRNA levels are significantly increased in the severe model compared to the moderate model (Fig. $3 \mathrm{~b}$ and $\mathrm{c}$ ). We conclude that the bitransgenic mice, which show increased DUX4-FL expression correlating with the degree of TMX treatment, resemble FSHD patient muscle biopsies, which show increased expression of known DUX4-FL target genes compared with control biopsies [26].

\section{Characterization of muscle function for three levels of phenotypic severity}

To determine if increases in DUX4-FL protein and target gene expression levels in skeletal muscles correlate 
with altered muscle function and strength, we performed treadmill exhaustion assays and ex vivo muscle physiology studies. Adult ACTA1-MCM control and bitransgenic mice (mild model) showed size differences between males, with bi-transgenic males being significantly smaller than controls $(\sim 26 \mathrm{~g}$ and $\sim 23 \mathrm{~g}$, respectively; Figure S6B and D), while females for both genotypes showed no significant size differences prior to TMX injection $(\sim 22 \mathrm{~g}$ and $\sim 21 \mathrm{~g}$, respectively; Figure $\mathrm{S} 6 \mathrm{~A}$ and $\mathrm{C}$ ). Therefore, male and female mice were analyzed separately to assess potential sex differences in presentation of the phenotypes. The treadmill analysis protocol consisted of running the mice on a slightly inclined treadmill, slowly increasing the speed until the mice could not run any longer, and measuring the time to fatigue, with a maximum assay time of $20 \mathrm{~min}$. We found these particular conditions (see the "Methods" section) provided highly consistent results and a readily assayable window for these three mouse models. Both male and female ACTA1-MCM control mice, injected with the appropriate TMX dose for the group being assayed, showed steady levels of near-maximum treadmill running fitness over the course of the assays (Fig. 4, blue lines). Similarly, treadmill fitness for male and female mild model mice was not significantly different from the ACTA1-MCM controls (Fig. 4, green lines). However, moderate and severe model mice were significantly less fit compared with controls (Fig. 4, red lines). Interestingly, both the moderate and severe models showed sex-specific treadmill fitness profiles in which

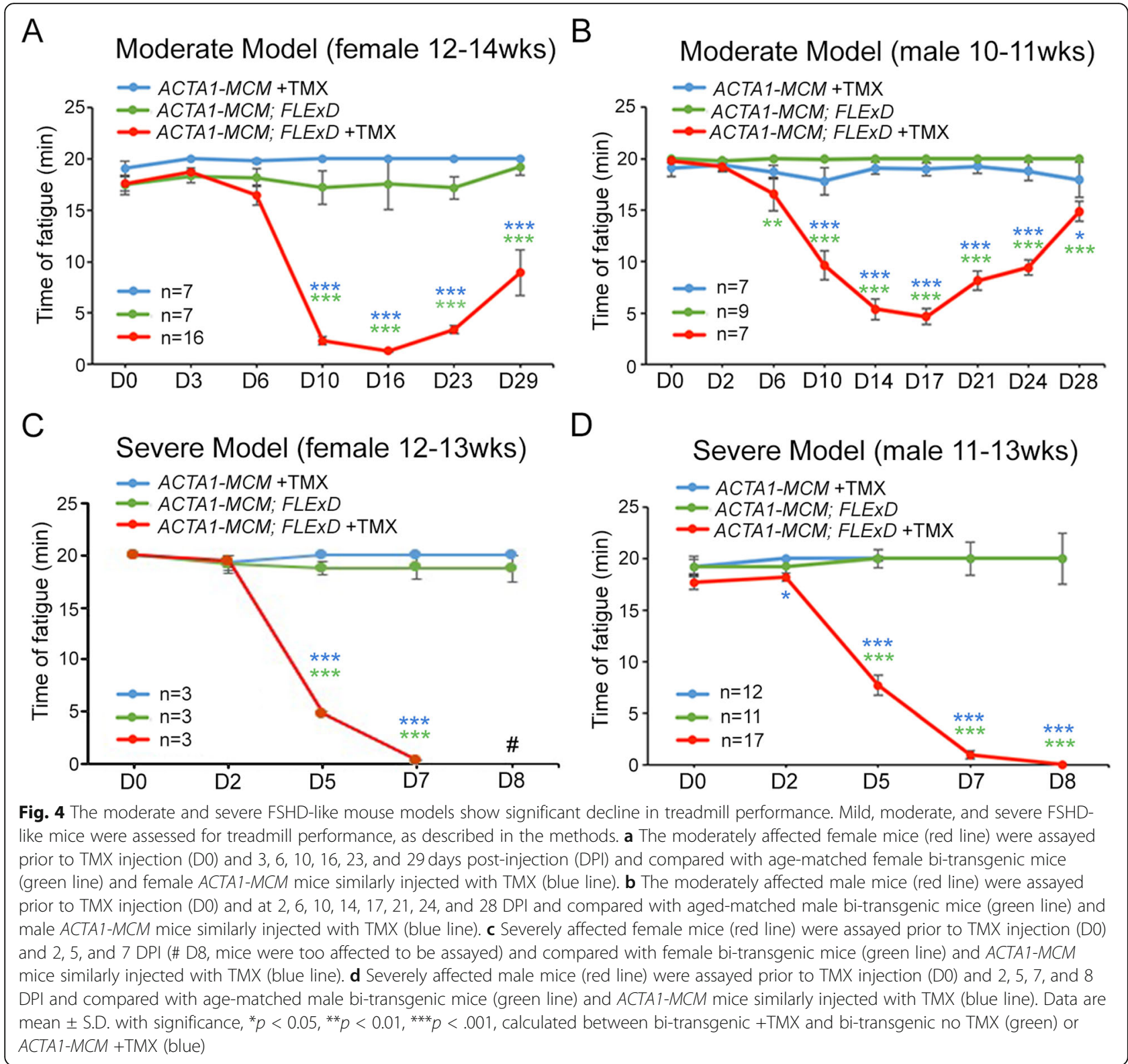


the female mice (Fig. 4a, c) were more severely affected than the male mice (Fig. 4b, d). Moderate female mice showed significant declines in fitness 10 days after TMX induction (MD10), dropping from near-maximum running times to less than $3 \mathrm{~min}$. This decline remained at MD16 before beginning to recover to $\sim 4$ min running at MD23 and $\sim 10$ min by MD29. In comparison, all male moderate model mice showed a significant decline starting at MD6 (running 15 min) which progressed more slowly than in females, running for $\sim 10 \mathrm{~min}$ at MD10 and $\sim 5 \mathrm{~min}$ at MD14 and MD17 before recovering to 15 min by MD28. Overall, although all moderately affected mice showed significant declines in treadmill fitness over the course of 4 weeks, female mice were more severely affected and recovered more slowly than male mice. For the severe model mice, female mice declined more rapidly than males, although both showed a significant decline in running time before fatigue, decreasing by over 10 min compared with controls by SD5, a point at which the moderate model mice were still unaffected. Female mice could not even begin the assay at SD7, while their male counterparts were slightly less fatigued at SD5 and were able to run a few seconds at SD7. These male mice reached the point of being unable to safely start the assay at SD8. All of these assay points indicated a much more severe phenotype than at any point during the assessment of the moderate model, and these severely affected mice had to be humanely sacrificed by $\mathrm{SD} 10$, with general movement in the cage greatly impaired and no signs of recovery. These sex-specific differences make it vitally important to analyze and compare mice of the same sex when performing fitness assays using both of these FSHD-like models.

Treadmill assays indicated that muscle use and/or function was impaired by induction of $D U X 4-f l$ expression in the moderate and severe mouse models. Ex vivo muscle contractile studies using the isolated extensor digitorum longus (EDL) were then performed on these mice to assess changes in muscle strength [59, 60, 79] (Figs. 5, S7, and S8). First, EDL muscles isolated from the mild model were compared with age-matched ACTA1-MCM mice (control) treated with the appropriate dose of TMX for the respective group isolated at TMX D14 or TMX D10 from the first injection. Interestingly, despite having similar treadmill endurance profiles as controls (Fig. 4), the EDL muscles from female mild model mice consistently showed significantly lower maximum absolute force (Figure S7) and specific force (maximum force normalized by cross sectional area, CSA) compared with ACTA1-MCM controls (Fig. 5). Male mild model mice were less affected and only showed a significant strength difference from controls with respect to maximum twitch force and maximum force frequency, and no significant change in specific force measurements (Figure S8A-F). However, both male and female mild models were less responsive to mid to high stimulation frequencies $(65-180 \mathrm{~Hz}) \mathrm{com}$ pared with controls (Figs. 5c and S8F). We conclude that chronic, low, mosaic DUX4-FL expression in even a few myofibers reproducibly produced a measurable decrease in isometric contractile strength of muscle that does not appear to affect treadmill fitness. Thus, this data suggests that these mild FSHD-like model mice may present a model of pre-symptomatic FSHD or an early symptomatic mild FSHD.

We similarly assayed the moderate and severe FSHDlike model mice for ex vivo muscle function, both of which showed significant differences in treadmill fitness compared with the ACTA1-MCM controls and the mild model mice upon TMX injection (Fig. 4). For the moderate model analysis, female mice were run on the treadmill until exhaustion, as above, prior to TMX injection, and then run twice per week until sacrificed and assayed at MD14, the peak of DUX4-FL protein expression (Fig. $2 \mathrm{~g}$ and $\mathrm{h}$ ) and impaired treadmill running (Fig. 4a). The isolated EDL muscles from the moderate model mice were significantly weaker and stiffer compared with the ACTA1-MCM controls (Figs. 5 and S6); however, these muscles only showed small, but significant, decreases in specific force measurements and stiffness when compared with the mild model. The DUX4dependent impairment of muscle function was much more striking in the severe model mice. Male and female mice were run on the treadmill until exhaustion, as before, prior to TMX injection and again at SD2, SD5, and SD7 (female) or SD8 (male), then sacrificed at SD10, the point of maximal fitness decline (Fig. 4c and d). The EDL muscles from both female (Fig. 5) and male (Figure S8) severe model mice showed $~ 3$ fold decreases in all specific force measurements, and muscles were significantly stiffer after eccentric stretches when compared with ACTA1-MCM controls and mild model mice. In addition, the severe model mice were virtually non-responsive to low-frequency stimuli $(<30 \mathrm{~Hz})$ and were severely impaired across the force frequency assay range (Figs. $5 \mathrm{c}$ and S8F). When compared with the moderate model mice, muscles from the severe model were again significantly weaker. Overall, we conclude that murine skeletal muscles can tolerate a very low level of DUX4-FL expression without significant impairment of function; however, increases in DUX4-FL expression eventually lead to muscle weakness and loss of function in a dose-dependent manner.

\section{Global mRNA expression analysis for moderate and severe FSHD-like mice}

To begin to identify the mechanisms and pathways disrupted by DUX4-fl expression in murine skeletal muscle, 


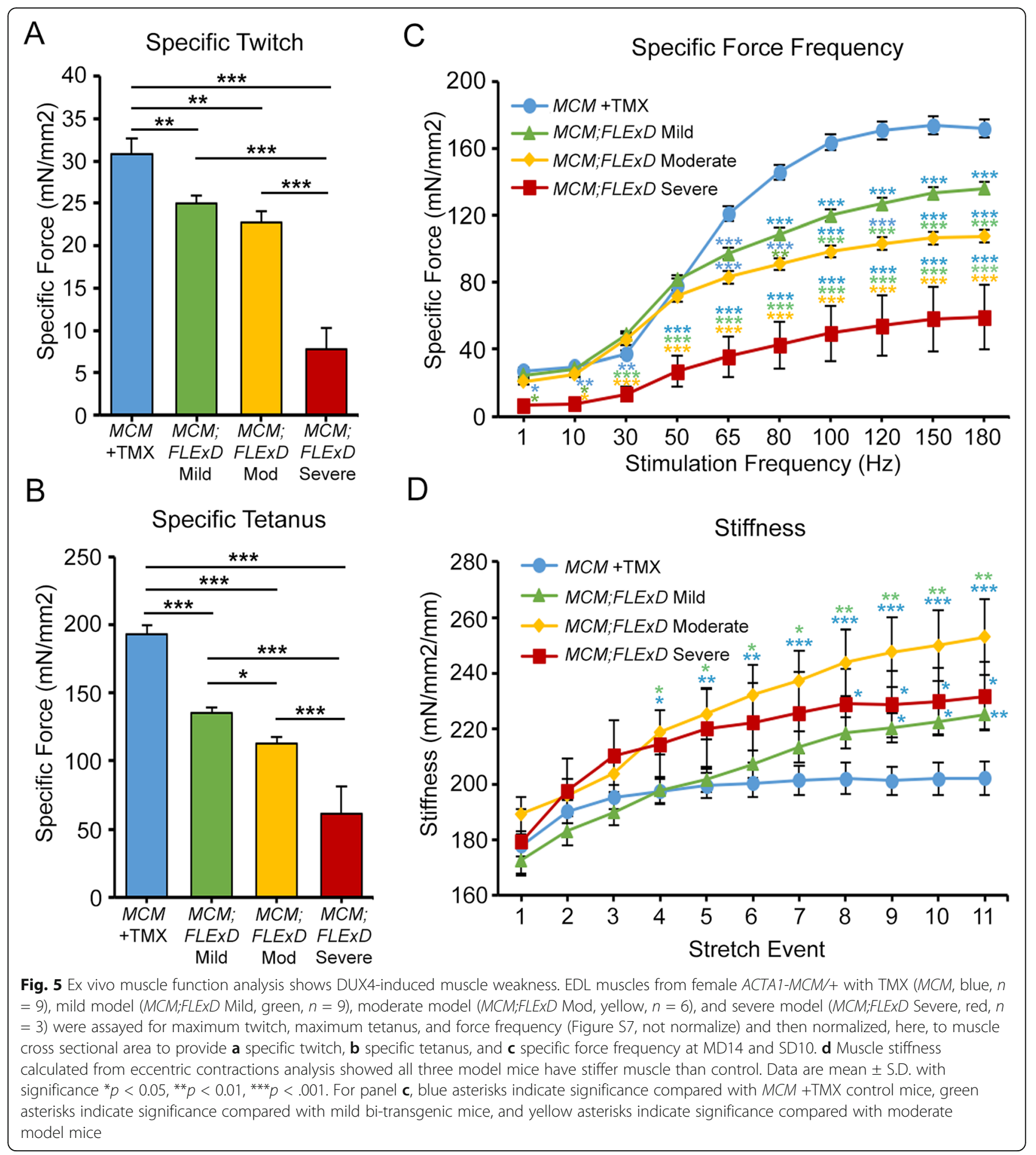

RNA-seq analysis was performed on gastrocnemius muscles isolated from control (ACTA1-MCM/+), FLExD/+ hemizygous, mild, moderate (MD9), and severe (SD9) bi-transgenic FSHD-like model mice (13 weeks old, $n=$ 3 each), and analyzed for global mRNA expression levels (Table S1). Genes with significant differential expression (>1.4-fold) from the ACTA1-MCM controls were identified (Table S2). The ACTA1-MCM/+ and FLExD/ + single transgenic mice only showed 3 genes differentially expressed ( 2 upregulated and 1 downregulated) between the mice (Fig. 6a and Table S2), which is consistent with our previous qRT-PCR studies showing no significant differences in expression of $D U X 4-f l$ or several prominent DUX4-FL targets between these mice 
[48]. In contrast, the transcriptomes for the mild, moderate, and severe models were significantly different from the ACTA1-MCM controls when analyzing genes significantly misregulated $>1.4$-fold (Fig. $6 \mathrm{~b}-\mathrm{d}$ and Table S2). The mild model showed 663 genes differentially upregulated and 192 genes differentially downregulated, the moderate model showed 1295 genes differentially upregulated and 852 genes differentially downregulated, while the severe model showed 2577 genes differentially upregulated and 1962 genes differentially downregulated compared with ACTA1-MCM controls. This included known murine DUX4 target genes previously identified from $\mathrm{C} 2 \mathrm{C} 12$ cells such as Wfdc3 [25]. However, when DUX4-induced genes (>2-fold) from murine skeletal muscle were compared with differential gene expression profiles from human FSHD patient muscle biopsies [26] there was very little overlap, with only 127 upregulated genes and 10 downregulated genes being the same (Table S3). This is actually not surprising since human DUX4 expressed in cultured mouse cells induces a gene set that only partially overlaps with DUX4 expression in cultured human cells [80, 81], and many functional DUX4 binding sites in the human genome are within retroelements that are lacking in or poorly conserved with mice [82].

Recently, an analysis of human FSHD transcriptome data has suggested that PAX7 regulated genes are aberrantly repressed in FSHD [83, 84]. PAX7 expression can suppress DUX4-FL cytotoxicity [85] in vitro and the PAX7 and DUX4-FL homeodomains are functionally interchangeable [40]. However, DUX4 and PAX7 have non-overlapping expression profiles during in vitro myogenesis of FSHD-derived stem cells [86], single-cell RNA-seq show DUX4-negative cells have a PAX7 repression signature [87], and there are no published reports of PAX7/DUX4 double-positive cells being found in FSHD biopsies or cell culture, all suggesting the PAX7-related mis-regulation is likely downstream of DUX4 expression in FSHD. Since PAX7/Pax7 are essentially functionally conserved between human and mouse [88], we analyzed our RNA-seq data similarly [87] for a Pax7 repression RNA signature (Figure S9). However, our analysis revealed that levels of both Pax7 and Pax7induced genes are in fact upregulated in response to DUX4 levels in the mouse models, which may be indicative of stimulated muscle repair and regeneration.

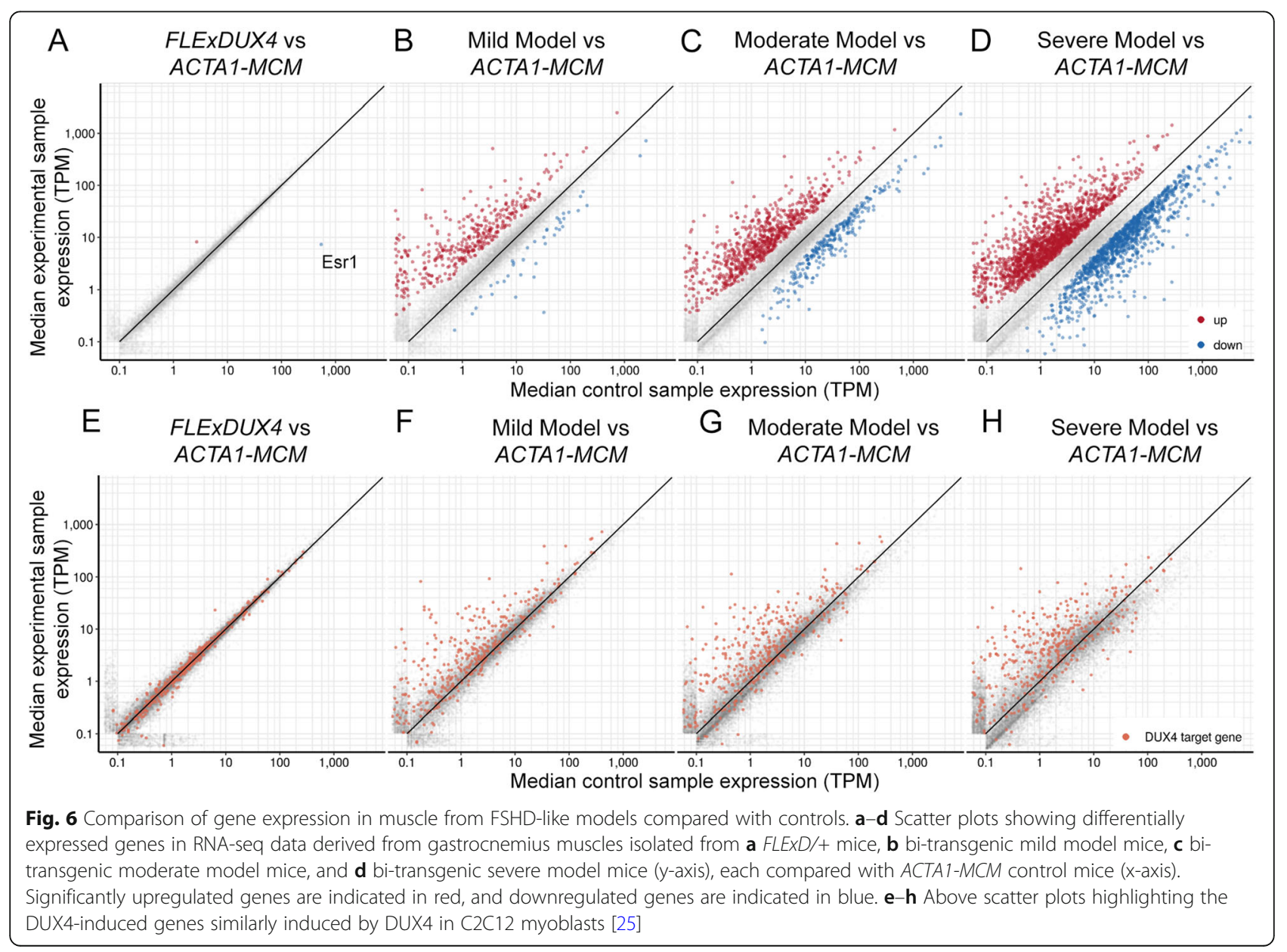


Despite the low overlap in specific misregulated genes between muscles from FSHD patients and FSHD-like mice, there is some conservation in DUX4-activated pathways in human and mouse [25], and the general DUX4-induced myopathic phenotype appears to be conserved across several species [42, 89-92]. DUX4 is proapoptotic and its expression is detrimental to muscle development and differentiation [7, 21, 38, 40, 42-44, 85, 89, 91, 93]. Expression of DUX4 stimulates genes that modulate the immune response [33], and FSHD patient biopsies show expression of immune genes, features of inflammation visualized by MRI, and immune cell infiltration [26, 35, 94-96]. Therefore, we performed gene ontology (GO) enrichment analysis on the differentially expressed genes (>1.4-fold change, Fig. 7) from the FSHD-like mild, moderate, and severe mouse models focusing on pathways consistent with FSHD (Superterms: Apoptosis, Cell cycle, Immune, and Muscle; Figs. 7 and S10 and Tables 2, S4, and S5). A similar GO analysis using RNA-seq performed on $\mathrm{C} 2 \mathrm{C} 12$ cells with inducible DUX4-fl expression [25] is shown for comparison and reveals differences between mouse muscle expressing human DUX4-fl and cultured murine cells expressing human DUX4-fl, the most prominent being the inversion of the immune genes group. However, since the DUX4-expressing $\mathrm{C} 2 \mathrm{C} 12$ cells express higher levels of DUX4 than any of the mouse models, we also performed the GO analysis at a higher threshold ( $>2$-fold) for expression changes (Figure S10) for an additional comparison.

DUX4-FL expression has been shown to inhibit nonsense-mediated decay, resulting in accumulation of mRNAs that would be typical substrates for NMD [37]. Therefore, we analyzed the RNA-seq data for aberrant alternative splicing events resulting in skipped exons (SE) or retained introns (RI) using MISO [63]. MISO identifies alternative splicing events based on predefined splicing events, taking advantage of existing knowledge and therefore is more accurate in characterizing alternative splicing events in RNA-seq data. The MISO analysis of the RNA-seq data revealed that the moderate and severe disease models had significant

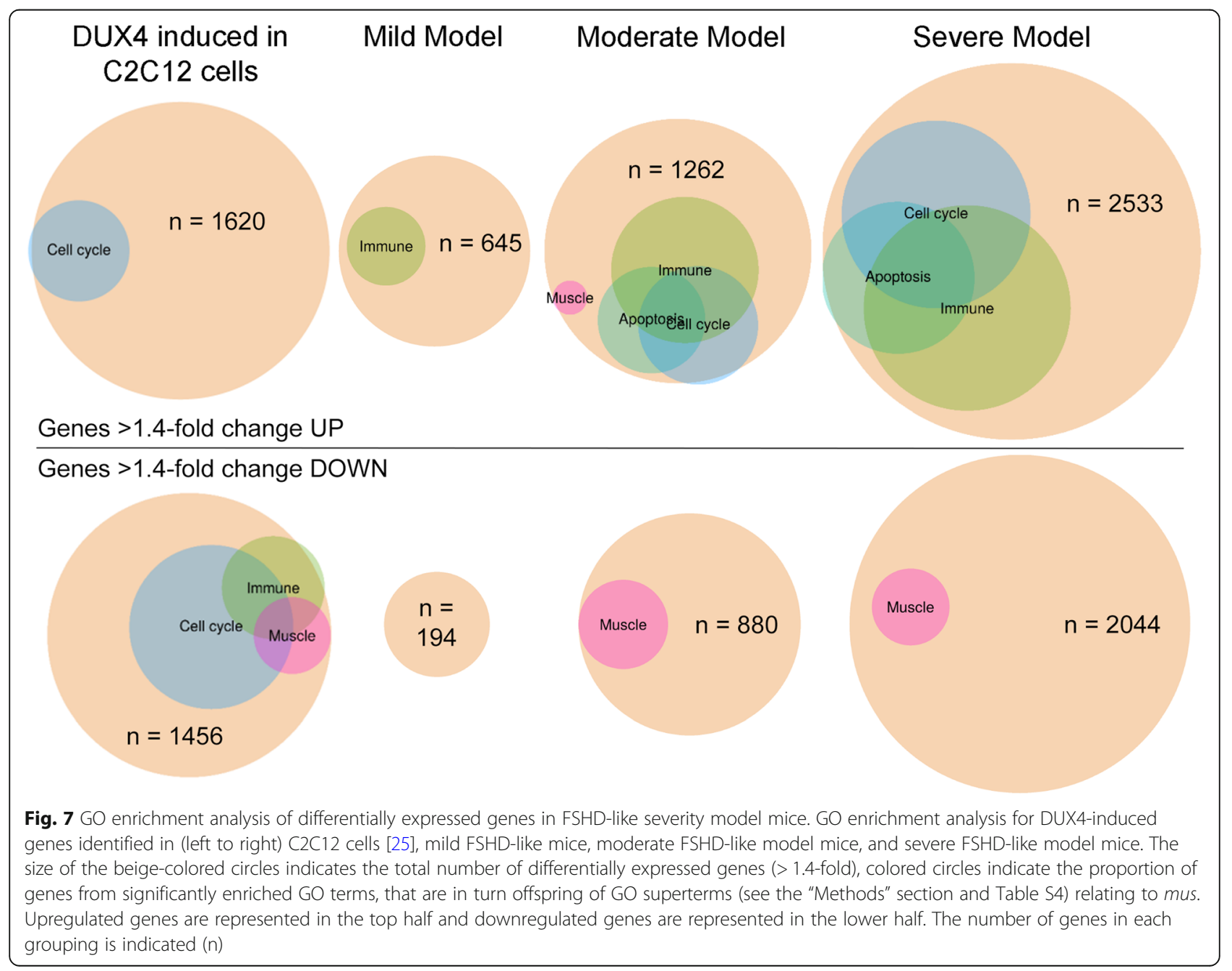


Table 2 GO superterms enriched in FSHD-like models

\begin{tabular}{|c|c|c|c|}
\hline Comparison & Status & $\begin{array}{l}\mathrm{GO} \\
\text { superterm }\end{array}$ & $\begin{array}{l}\text { \% of genes } \\
\text { associated }^{\text {a }}\end{array}$ \\
\hline iDUX4 Dox vs vehicle & Up & Apoptosis & 16.42 \\
\hline iDUX4 Dox vs vehicle & Up & Cell cycle & 12.55 \\
\hline iDUX4 Dox vs vehicle & Up & Immune & 0.53 \\
\hline iDUX4 Dox vs vehicle & Down & Cell cycle & 39.25 \\
\hline iDUX4 Dox vs vehicle & Down & Immune & 7.07 \\
\hline iDUX4 Dox vs vehicle & Down & Muscle & 4.99 \\
\hline $\begin{array}{l}\text { Moderate model vs } \\
\text { MCM }\end{array}$ & Up & Immune & 30.06 \\
\hline $\begin{array}{l}\text { Moderate model vs } \\
\text { MCM }\end{array}$ & Up & Cell cycle & 24.91 \\
\hline $\begin{array}{l}\text { Moderate model vs } \\
\text { MCM }\end{array}$ & Up & Apoptosis & 10.29 \\
\hline $\begin{array}{l}\text { Moderate model vs } \\
\text { MCM }\end{array}$ & Down & Muscle & 8.23 \\
\hline Severe model vs MCM & Up & Immune & 31.05 \\
\hline Severe model vs MCM & Up & Cell cycle & 26.43 \\
\hline Severe model vs MCM & Up & Apoptosis & 16.95 \\
\hline Severe model vs MCM & Up & Muscle & 0.70 \\
\hline Severe model vs MCM & Down & Muscle & 14.84 \\
\hline
\end{tabular}

Superterms listed in Table S4

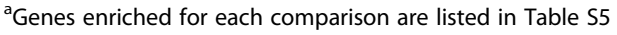

increases in SE and RI events and that the severe model had significantly more SE and RI events than the moderate model (Tables 3 and S6). This data supports that increased DUX4-fl expression and increased disease severity is correlated with increased SE and RI, which suggests a decrease in RNA quality control.

\section{Histological analysis of FSHD-like model mice}

The three severity levels of myopathic mouse phenotypes (Table 1) were analyzed for FSHD-like DUX4dependent histopathology [30, 35, 97]. The initial analysis of the mouse models showed different, musclespecific levels of transgene recombination in all three bitransgenic severity models (Fig. 1). Therefore, cryosections for histological analysis were generated from multiple muscles, including TA, gastrocnemius, soleus, quadriceps, and heart, for all three models. These muscle sections were then analyzed by hematoxylin and eosin (H\&E) staining to assess fiber morphology, number, and centralized nuclei (Figs, 8, 9, and 10 and S11 and S12), embryonic myosin heavy chain (eMyHC/Myh3) IF and myostatin expression to assess muscle fiber regeneration (Figs. 11, S13, and S14), TUNEL assay to assess apoptosis (Figs. 12, 13, and S15), and picrosirius red (SR) staining to assess fibrosis (Figs. 14, S16, and S17). The previously described time-courses of treadmill exhaustion running were performed using female mice for the moderate model, with mice sacrificed for histology at
Table 3 Alternative splicing analysis

\begin{tabular}{llll}
\hline Phenotype & Mouse ID* & \#SE & \#Rl \\
\hline ACTA1-MCM/+ & MCM-1127 & 9619 & 1905 \\
& MCM-1246 & 9775 & 1934 \\
& MCM-1349 & 9890 & 1940 \\
FLEXD/+ & $9761 \pm 95$ & $1926 \pm 14$ \\
& FLEXD-1358 & 9704 & 1910 \\
& FLEXD-1367 & 9745 & 1913 \\
& FLEXD-1378 & 9828 & 1934 \\
& & $9759 \pm 46$ & $1919 \pm 10$ \\
Moderate model & dTGM-1236 & 10,987 & $p=0.30383$ \\
& dTGM-1308 & 10,917 & 2278 \\
& dTGM-1331 & 10,940 & 2261 \\
& & $10,948 \pm 26$ & $2265 \pm 9$ \\
& & $p=0.000064$ & $p<0.00001$ \\
Severe model & dTGS-1047 & 11,691 & 2505 \\
& dTGS-1066 & 11,658 & 2456 \\
& dTGS-1079 & 11,560 & 2466 \\
& & $11,636 \pm 51$ & $2476 \pm 20$ \\
& & $p=0.000014$ & $p<0.00001$ \\
\hline & &
\end{tabular}

$p$ values calculated compared with ACTA1-MCM/+

${ }^{*}$ Mouse ID correlates with RNA-seq data in Table S1

MD3, MD6, MD14, and MD28 (Fig. 8), and using male mice for the severe model, with mice sacrificed at SD3, SD6, and SD9 (Fig. 9). Sex and age-matched ACTA1$M C M$ mice injected with appropriate levels of TMX for the model were used as controls, and the mild bitransgenic (No TMX) model mice were assayed for comparison (D0).

Analysis of the H\&E histology indicated that for the mild model muscles (Fig. 8 e-h and Fig. 9 e-h), very low mosaic DUX4-fl expression leads to minor changes in histology, the most notable being increased percentage of myofibers containing centralized nuclei compared with ACTA1-MCM control muscles $(3-10 \%$ vs $<1 \%$, respectively; Fig. 10). Interestingly, there are anatomical musclespecific effects that correlate with the level of transgene recombination. The soleus muscles, which have the lowest levels of leaky transgene recombination in muscle assayed for the mild model, have 3\% myofibers with central nuclei, while the TA muscles, which have a higher recombination rate and thus more DUX4-FL-expressing nuclei (Fig. 1b), have $\sim 10 \%$ myofibers with central nuclei (Fig. 10), suggesting that DUX4-FL expression is driving the formation of fibers with central nuclei.

In contrast to the mild model, the histology from the moderate (Fig. 8i-x) and severe (Fig. 9 i- Fig. 10 t, and S11) model mice showed greater effects of DUX4-fl expression, including variability in skeletal muscle fiber 




size, round and triangular fiber shapes, few fiber numbers, significant increases in the percentage of fibers with centralized nuclei, an influx of mononuclear cells, and ultimately an apparent decrease in structural integrity of the muscle. This histopathology accumulated over time and correlated with loss of muscle function. For example, in the moderate model histology, the few mononuclear cells that have infiltrated by MD6 dramatically increase by MD14. Similarly, the percentage of fibers with centralized nuclei jumps significantly between MD6 (4\%, 10\%) and MD14 (20\%, 35\%) and MD28 (38\%, 52\%) in both the soleus and TA, respectively (Fig. 10). The severe model has a similar percentage of myofibers with centralized nuclei at SD6; however, there is an increase by SD9 showing $\sim 10 \%$ in the soleus and $\sim 20 \%$ in the
TA. Importantly, as seen in the mild model, these models showed anatomical muscle-specific differences in histopathogenic features, correlating with musclespecific levels of transgene recombination (Fig. 1b), consistent with DUX4-FL expression leading to an atrophic phenotype [38]. For example, the soleus muscle, which shows the highest level of TMX-responsive transgene recombination, also appears to have the greatest degree of histopathology for each model, including mononuclear cell infiltration, disrupted muscle integrity (Fig. 8 k, o, s and Fig. 9 O, S), and fewer fibers per cross section albeit with a higher percentage of centralized nuclei (Fig. 10). The quadriceps showed the lowest level of transgene recombination and similarly showed the least amount of histopathology for the analyzed skeletal muscles. The 


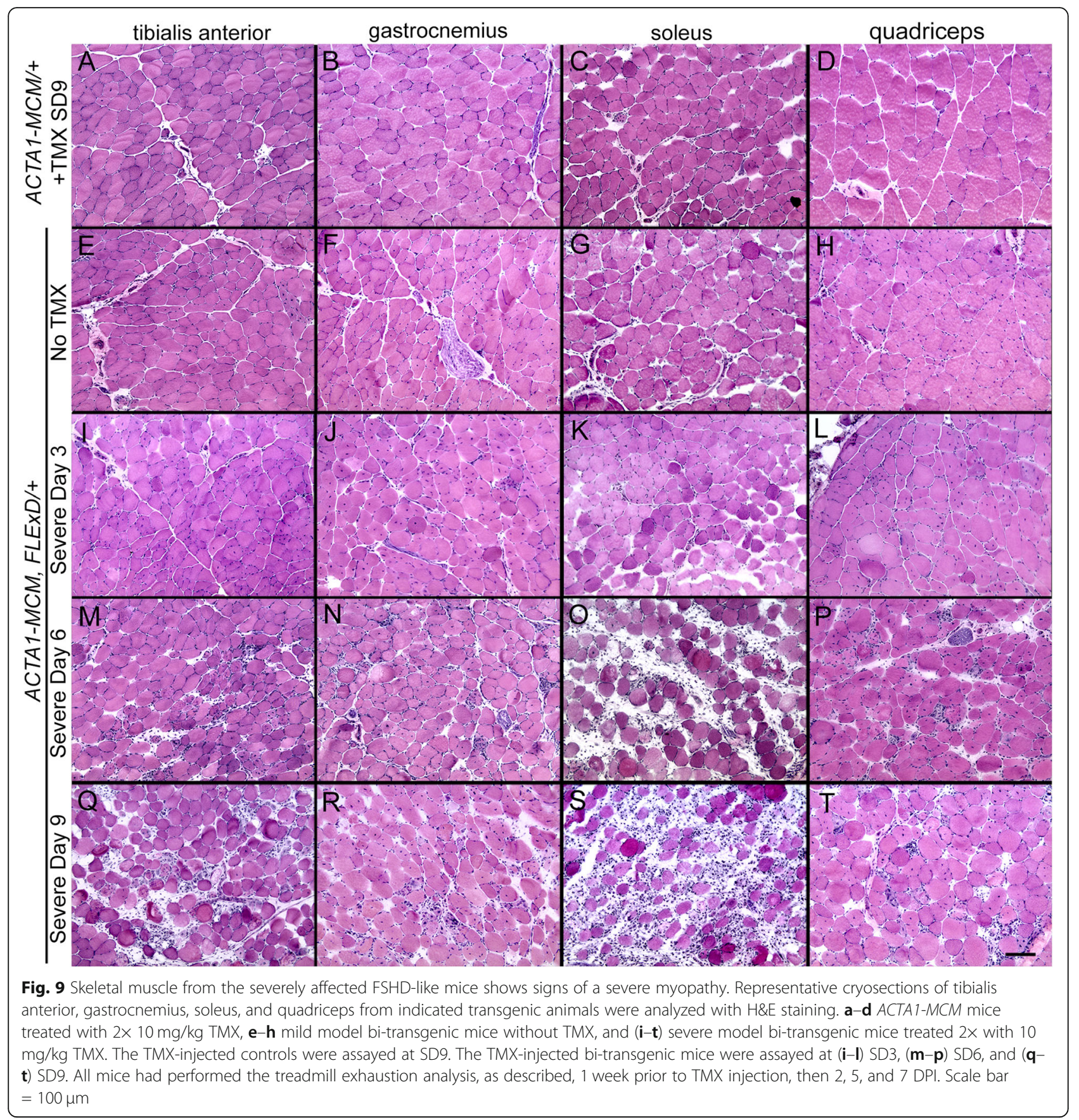

heart, which showed no transgene recombination or expression, did not show any pathology even in the severe model (Figure S12). Overall, the skeletal muscle histopathology in these models was progressive and the increased severity reflected increased DUX4-FL expression levels. This further supports that the extent of pathophysiology in these mouse models correlates with the level of transgene recombination (Fig. 1b) and DUX4-fl expression (Figs. 2 and 3).
The centrally positioned nuclei in myofibers are a common feature of many myopathies, including FSHD [97], and are considered a sign of repair and regeneration of the myofiber [98]. Interestingly, all three severity models of FSHD-like mice show increased centralized nuclei, especially following DUX4-FL induction (Fig. 10). Therefore, we analyzed muscles from these models for expression of eMyHC protein (Figs. 11 and S12), a marker for newly regenerating myofibers and dystrophic 


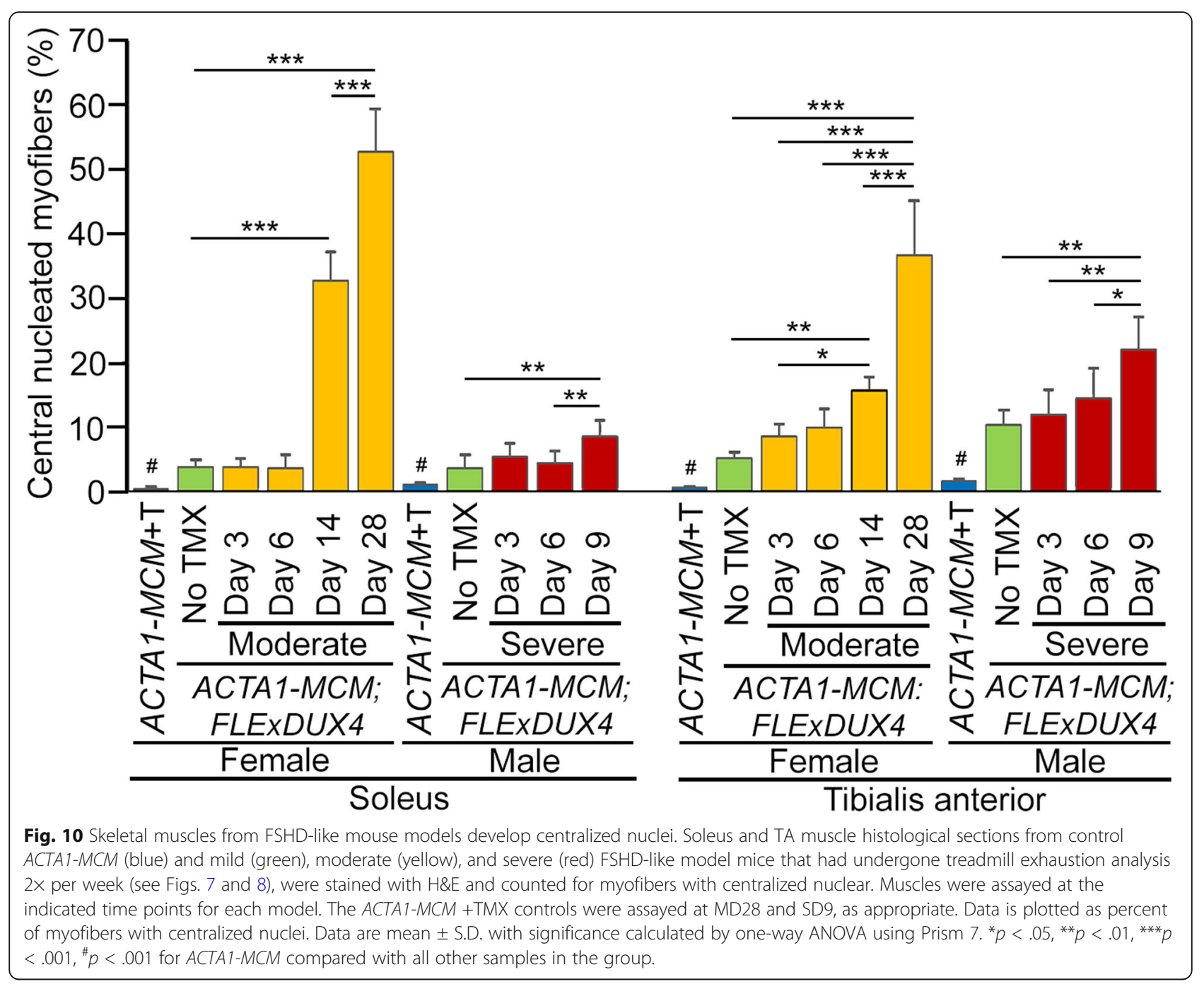

muscle [99], and expression of Myostatin (Mstn)/Gdf-8 (Figure S13), a negative regulator of muscle growth and remodeling in adult muscle [100]. Adult mouse skeletal muscles have very few myofibers that express the eMyHC isoform under normal healthy conditions [101]. However, regenerating myofibers re-express many developmental isoforms of muscle proteins, including eMyHC, which can be detected within 3 days of injury and whose expression can persist for up to 3 weeks [102-104]. Therefore, a time course study of eMyHC expression after DUX4-fl induction was performed on TA muscles (Fig. 11). As expected, the ACTA1-MCM controls showed no detectable expression of eMyHC in response to TMX (Figs. 11a-c and S12). Interestingly, the mild model mice, which have chronic low mosaic expression of DUX4-FL, similarly showed no detectable expression of eMyHC (Figs. 11K, L, S, T and S12), indicating that myofibers with centralized nuclei in the mild model are remnants of an old regeneration event. In contrast, both the moderate model (Figs. 11E-J and S12) and severe model (Figs. 11M-R and S12) showed high levels of eMyHC, peaking at MD14 and SD9, respectively, thus confirming that the spike of DUX4-FL expression at these moderate and severe levels activates the skeletal muscle regeneration program. In contrast to the increased eMyHC levels, expression of Mstn mRNA decreased in TA muscles as DUX4 levels and severity of pathology increased (Figure S13), which similarly would correlate with the induction of muscle regeneration. Together, these results show increased DUX4 expression leads to the muscle remodeling and regeneration.

The activation of muscle fiber regeneration after induction of DUX4-FL expression suggests that DUX4-FL is causing muscle damage. The GO analysis of differentially induced genes showed that muscles from the moderate and severe models are enriched for genes in apoptotic pathways (Fig. 7, Table 2). As mentioned, DUX4-FL is a pro-apoptotic protein, its expression is highly toxic to muscle cells in culture [7, 21, 44, 105], and an increased apoptosis rate compared is a feature of 


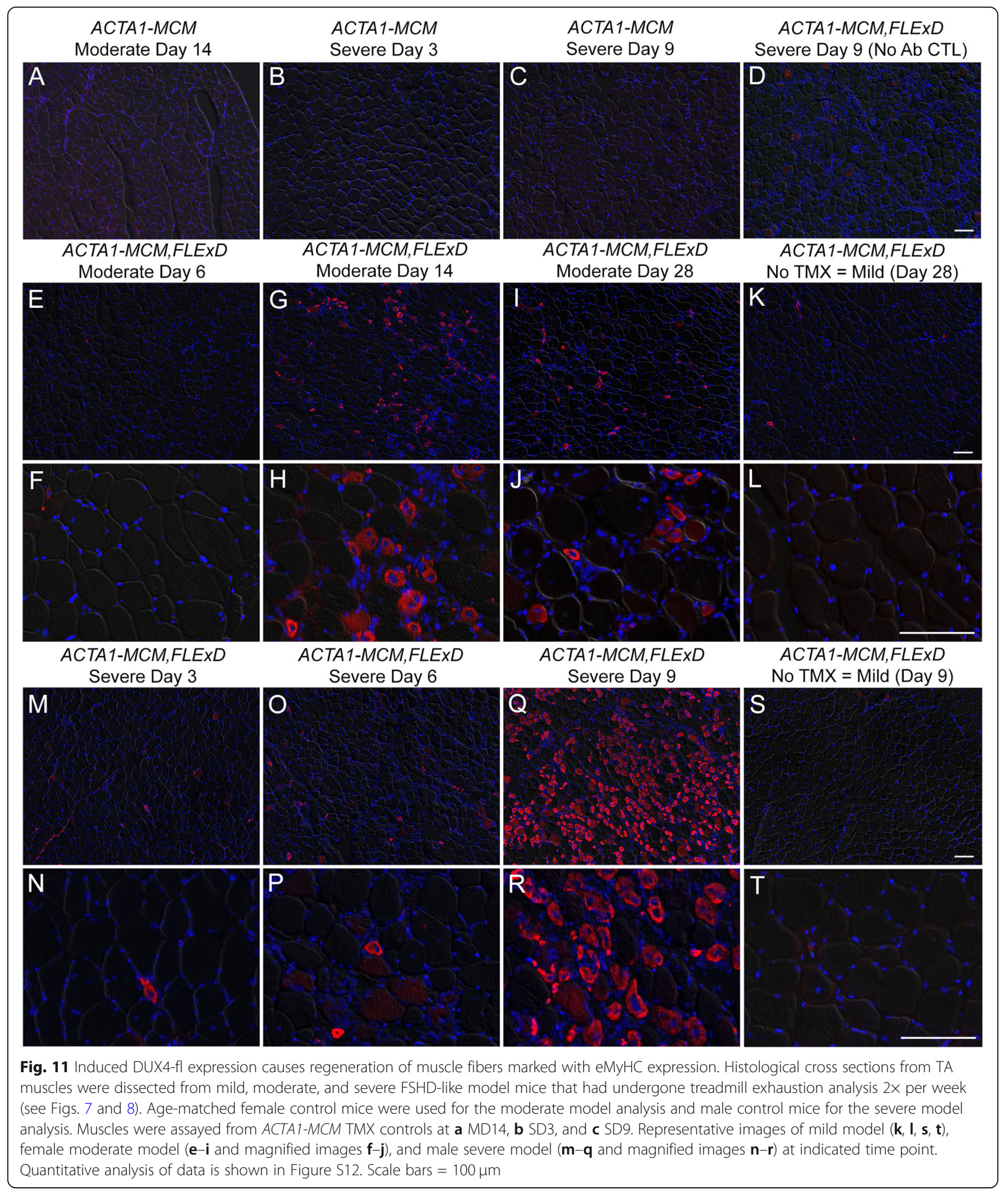

FSHD muscle [106]. To assess apoptosis in the three FSHD-like severity models, TUNEL assays were performed on TA muscles across the prior DUX4-FL induction time-courses in both the moderate and severe models as well as age-matched mild (No TMX) mice
(Figs. 12 and 13, respectively and Figure S14). In the moderate model, TUNEL-positive nuclei appeared by MD6, were prevalent at MD14, and were nearly absent by MD28 (Fig. 12a-c). Similarly, the severe model showed TUNEL-positive nuclei by SD6, with a 2-fold 


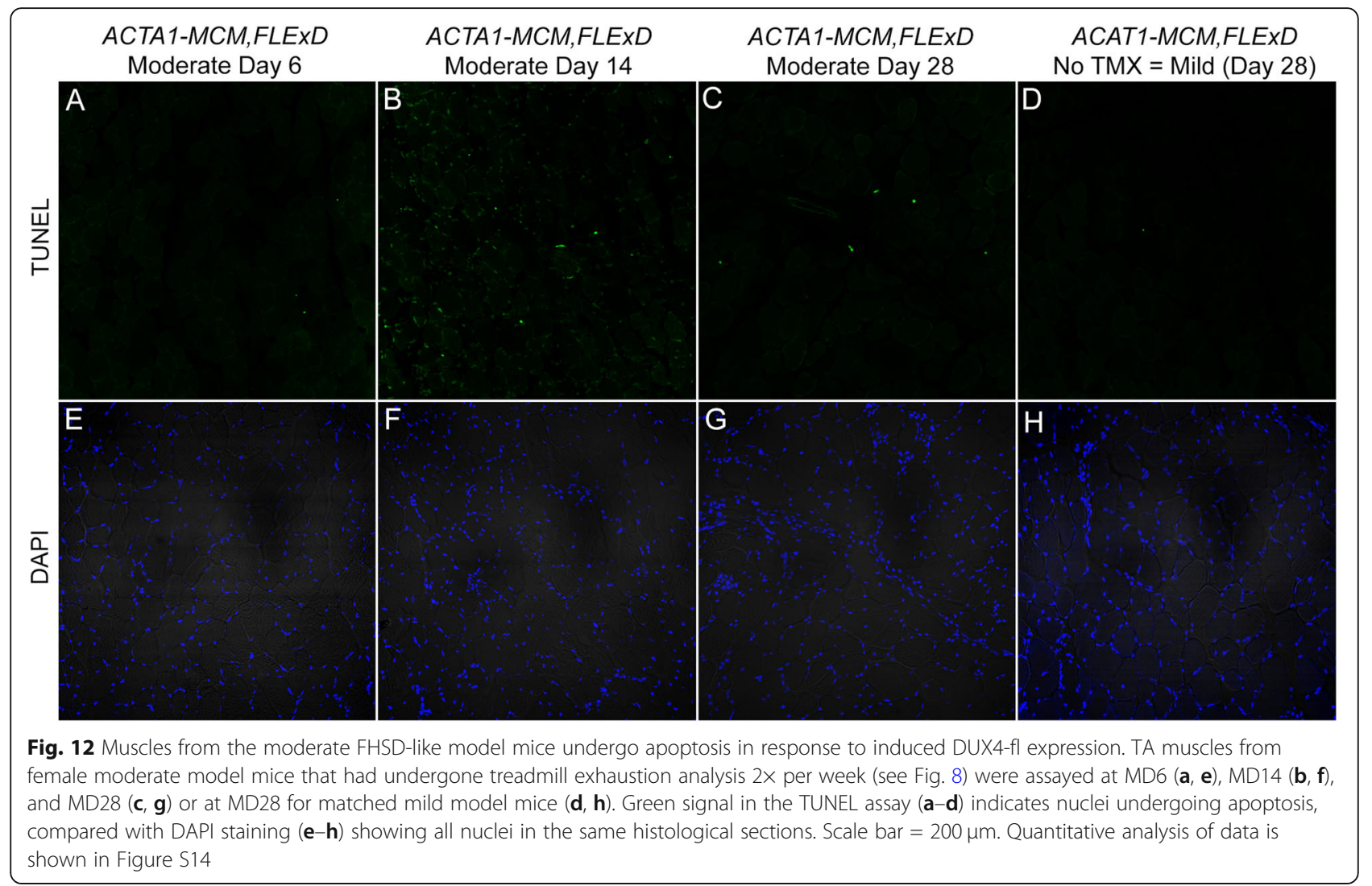

increase by SD9 (Fig. 13a-c). Interestingly, muscles from the mild model showed no indication of apoptosis and were similar to muscles from ACTA1-MCM controls (Fig. 13, compare panels D and L). Thus, the moderate and severe models show dose-dependent DUX4-FLinduced apoptosis following a similar time course as muscle weakness and decreased function and correlating with the activation of muscle regeneration.

Muscle biopsy data indicate fibro-fatty replacement in muscles of FSHD patients increasing with severity [30, 35, 97]. Muscle fibrosis, caused by stimulated fibroblast growth resulting in deposits of extracellular matrix between myofibers, leads to the loss of muscle architecture and decreased muscle function [30, 107-110]. The extent of fibrosis is typically quantified using histological methods and staining for collagen [58, 111]. Therefore, cross sections of the TA muscles isolated from the above series of control, mild, moderate, and severe FSHD-like mice were assayed for the extent of fibrosis developing over time using SR staining (Figs. 14, S15, and S16). The muscles from control ACTA1-MCM/+ and mild FSHDlike model mice had similar low levels $(\sim 2 \%$ fibrotic area) of fibrosis (Fig. 14a, f, g and Figure S15). The moderate model had similar control levels of fibrosis at MD3 and MD6; however, this model showed a small but significant $50 \%$ increase in fibrosis by MD14 and MD28 (Fig. 14B-E and Figure S15). The severe model showed increased fibrosis by SD3 and a maximal 2.5-fold increase in fibrosis (5.5\% fibrotic area) at SD9 (Fig. $14 \mathrm{~h}-\mathrm{j}$ and Figure S14). Overall, the level of accumulated fibrosis is small in the moderate and severe models; however, it should be noted that these models only provide a short time frame for fibrosis to form. The heart, which does not express detectable DUX4-fl in any of the models, showed no signs of fibrosis in any of the models (Figure S16).

\section{Discussion}

Modeling FSHD in transgenic mice has historically been very difficult despite the fact that FSHD is a gain-offunction disease seemingly amenable to transgenic DUX4 overexpression $[78,90,92]$. While the human DUX4 gene has a conserved developmental role with Dux family members found in other mammals, including the mouse, there is significant divergence at the DNA and protein sequence level as well as in the spectrum of species-specific target genes [25, 80, 112]. In addition, because DUX4-FL is highly cytotoxic for many somatic cells, leaky expression during development has been problematic, and surviving mice can be severely phenotypic and difficult to breed [91]. However, the FLEXD mice we recently developed overcame many of these previous limitations [48]. Both male and female mice are fertile and easy to breed, male 


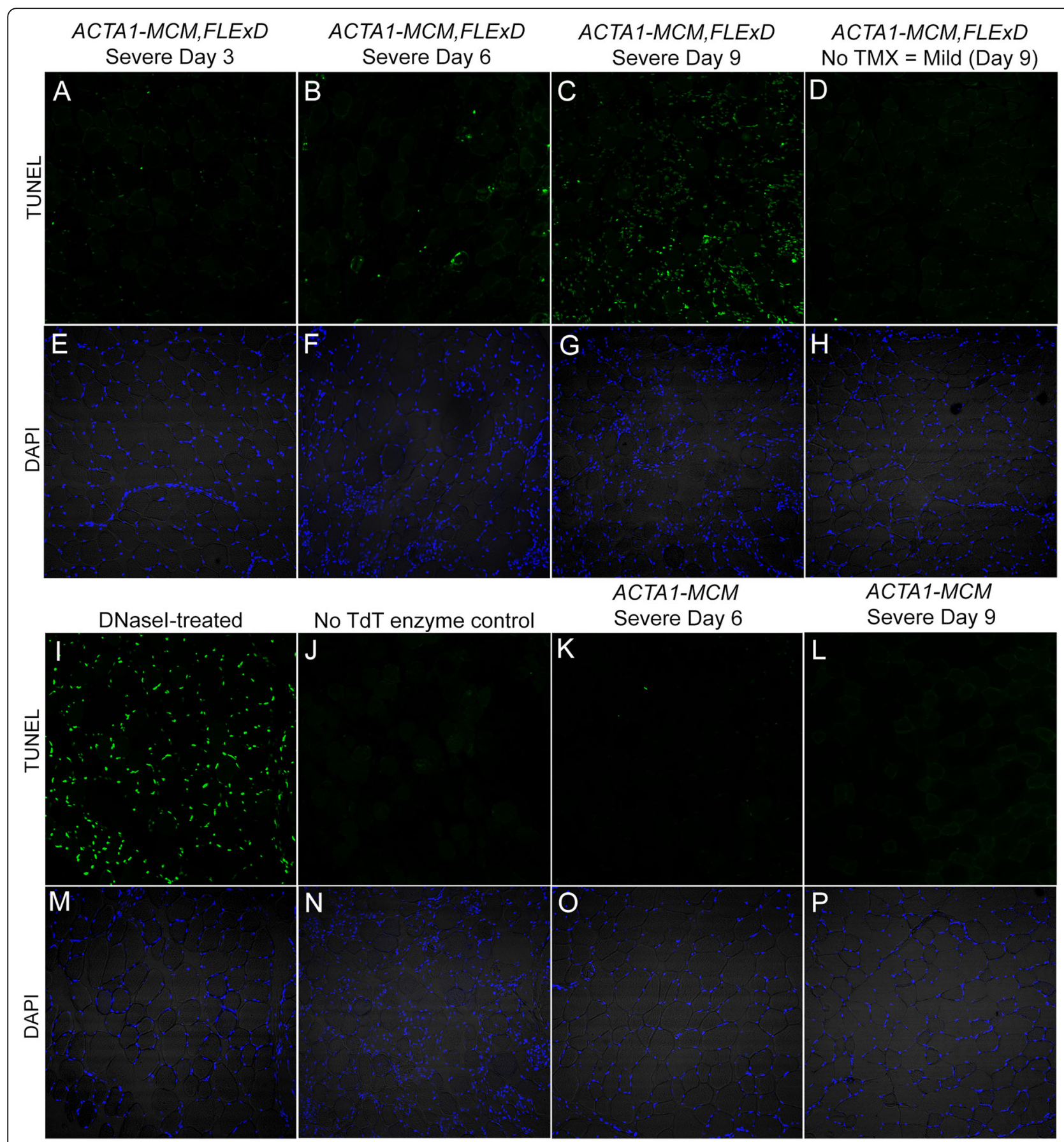

Fig. 13 Muscles from the severe FSHD-like model mice start to undergo apoptosis within 6 days of induced DUX4-fl expression. TA muscles from male severe model mice that had undergone treadmill exhaustion analysis (see Fig. 9) were assayed at SD3 (a, e), SD6 (b, f), and SD9 (c, g). $\operatorname{ACTA1-MCM~}(\mathbf{k}, \mathbf{l}, \mathbf{o}, \mathbf{p})$ and mild FSHD-like model mice $(D, H)$ were analyzed at indicated time point. Green signal in the TUNEL assay $(\mathbf{a}-\mathbf{d}$, $\mathbf{i}-\mathbf{I})$ indicates nuclei undergoing apoptosis, compared with DAPI staining $(\mathbf{e}-\mathbf{h}, \mathbf{m}-\mathbf{p})$ showing all nuclei in the same histological sections. DNase-I treated histological section of ACTA1-MCM (i, $\mathbf{m})$ and TUNEL staining of the severe model SD9 sample without the TdT enzyme $(\mathbf{j}, \mathbf{n})$ are used as positive and negative controls for TUNEL staining, respectively. Scale bar $=200 \mu \mathrm{m}$. Quantitative analysis of data is shown in Figure S14

or female transgenic mice can be produced either as transgene heterozygotes or homozygotes, which can live more than 1.5 years, and, when mated with an inducible Cre line of mice, bi-transgenic mice allow for investigator- controlled increased expression of DUX4-fl mRNA and protein resulting in FSHD-like muscle pathology [48]. Here, we report the characterization of a series of phenotypic FSHD-like mouse models varying in severity from 


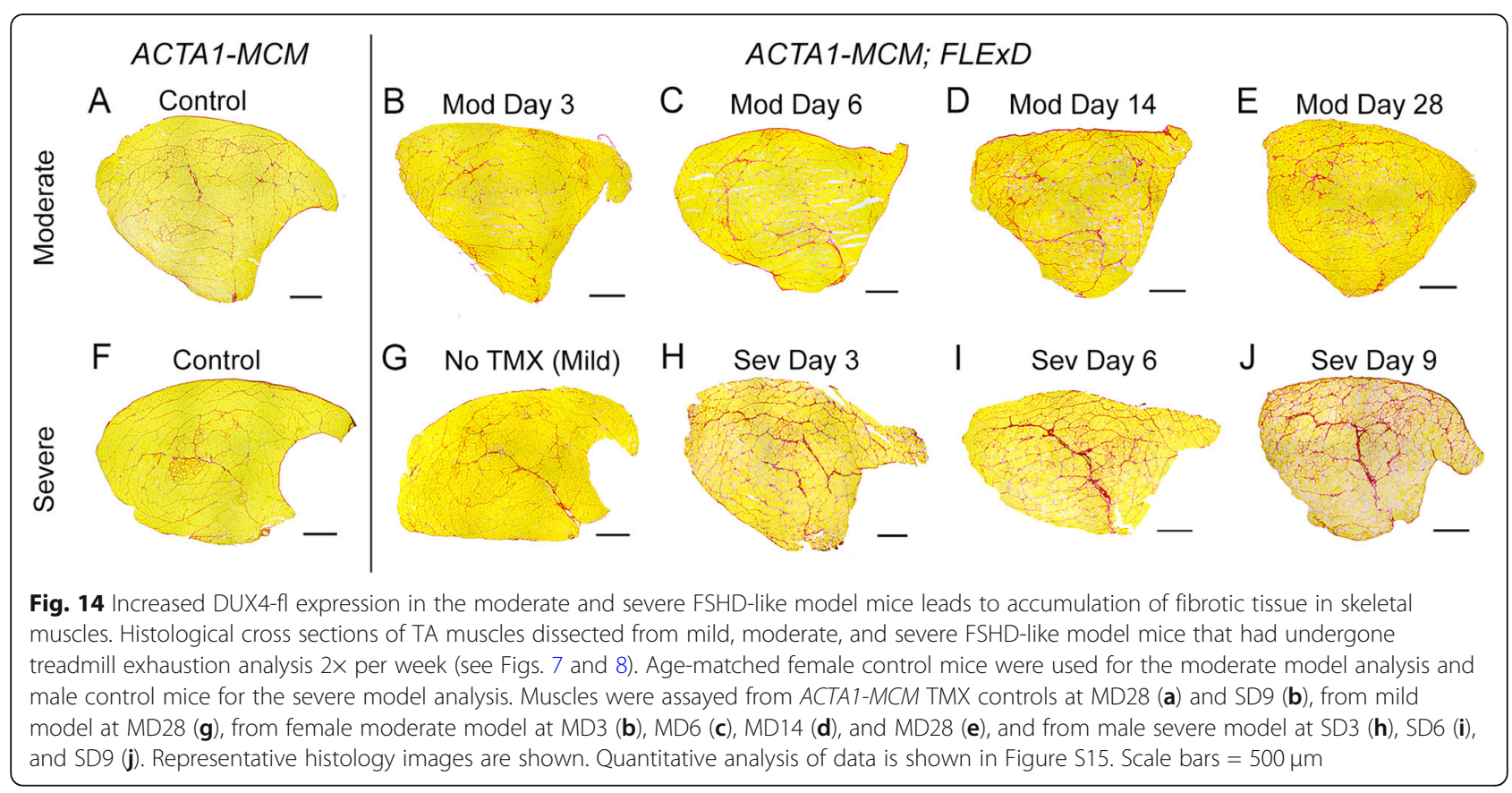

mild to severe, generated using the FLExD conditional DUX4-fl transgenic mouse line crossed with ACTA1$M C M$ TMX-inducible mice and identify important considerations for using these models. We demonstrate that these bi-transgenic mouse severity models recapitulate many aspects of FSHD pathophysiology, thus providing suitable models for therapeutic interventions targeting DUX4-fl mRNA, protein, and potentially certain downstream pathways, with several key caveats. In particular, it is important for those working on these models to keep in mind the described anatomical muscle-specific and sexspecific differences in pathology and disease progression as well as the potential impact the microbiome and different mouse facilities may have on phenotypes $[75,76]$.

\section{Mild FSHD-like mouse model}

The ACTA1-MCM; FLExD bi-transgenic mouse, in the absence of any TMX induction, has mosaic expression of DUX4-fl mRNA and protein and provides an excellent model of mild, pre-symptomatic FSHD. This is because the TMX-inducible Cre fusion protein produced in skeletal muscles by the ACTA1-MCM transgenic line exhibits leakiness into nuclei, resulting in Cre activity in the absence of TMX in a fraction of nuclei. Thus, in the ACTA1-MCM;FLEXD bi-transgenic mice, this results in recombination of the DUX4 transgene and low mosaic expression of DUX4-FL protein in skeletal muscles throughout their lifetime. Importantly, although this leaky recombination is specific to skeletal muscle, it is not uniform among skeletal muscles, with different anatomical muscles exhibiting different, but consistent, levels of recombination and thus DUX4-fl expression
(Fig. 1b, e.g., soleus is low and quadriceps is high). Thus, the situation in this mild model is similar to that in presymptomatic or asymptomatic FSHD patients. These mice live with a chronic, low-level, mosaic expression of DUX4-FL in a fraction $(<10 \%)$ of muscle fibers, yet phenotypically the mice appear healthy and behave normally, with no changes in overall fitness or lifespan.

Although these mild mice appear outwardly healthy, the low-level recombination produces several assayable phenotypes. The mild phenotype manifests as increased expression of DUX4-FL target genes (Fig. 3), $5-10 \%$ of myofibers with centralized nuclei at 10-12 weeks of age (Figs. 8 and 10), and 40\% decreased capacity for muscle force generation in female (but not male) mice, assayed ex vivo (Figs. 5, S7, and S8). There are also small but significant differences between males and females with respect to histology and centralized nuclei that need to be taken in to account. Overall, there is some low-level muscle pathology and new fiber regeneration, however, the mice do not exhibit increased apoptosis, immune cell infiltration, or increased fibrosis. The model is readily scalable, highly reproducible, and, considering that these mice live $>1.5$ years (female $n=43$, male $n=20$, to date), provides a DUX4-fl expression model that is amenable to longevity studies for efficacy of putative DUX4-targeted therapeutics. Thus, while the mild model is likely the easiest to work with and imposes no time limits on treatments, investigators must be careful in respect to sex, using a significant number of both sexes and analyzing them separately, which ages are used since this is a chronic accumulation pathology model, and which specific muscles to assay or treat. 


\section{Moderate FSHD-like mouse model}

Similar model-specific effects need to be taken into account when injecting TMX to generate the moderate and severe models, but these are even more pronounced. Importantly, while the moderate model showed consistently different levels of TMX-induced recombination between anatomical muscles (Fig. 1b), these were different from the leaky recombination in the mild model and more likely a reflection of the difference in TMX accessibility to various muscles. The moderate model mice also showed significant differences between males and females with respect to weight (Figure S6), treadmill profiles (Fig. 4), and muscle physiology (Figs. 5 and S7), with females being more severely affected by all metrics. With respect to appearance and progression of pathology, and, as opposed to the mild model, the moderate model mice show DUX4induced apoptosis (Fig. 12). DUX4-FL protein expression and apoptosis peak at MD14, at which point there is also an increase in $\mathrm{eMyHC}$ positive, newly regenerated fibers as wells as fibrosis (Figs. 11, 14, and S16). Muscles at this stage produce $\sim 60 \%$ of the force produced by ACTA1MCM controls (Fig. 5). Analysis of global differential gene expression supports the activation of apoptosis, the immune response, and the cell cycle, all three of which are much larger groupings than enriched in $\mathrm{C} 2 \mathrm{C} 12$ cells expressing DUX4. This illustrates a key difference between performing studies in vitro using single-cell types overexpressing DUX4 compared with studies of intact muscle expressing mosaic levels of DUX4 and containing all associated cell types (Fig. 7).

A key component of the moderate model is that after MD14 both male and female mice recover on their own, regaining $\sim 50 \%$ treadmill running by MD28, which coincides with decreases in apoptosis, and eMyHC staining, although fibrosis remains. This is likely because DUX4-FLpositive myofibers die and are being repaired and replaced using satellite cells that did not undergo transgene recombination and thus have not activated DUX4 expression. Therefore, it is imperative to have the proper controls when using these models for preclinical testing of therapeutics. However, this also presents an opportunity whereby the mice can be re-injected with TMX at some point during treatment and progressive decline of the model can be assessed over several months. Preliminary experiments in our lab suggest that this is a viable possibility that needs further investigation and characterization. In addition, TMX can be adjusted to single higher-dose injections or multiple lower-dose injections to refine the model to meet investigational needs. The flexibility and tunability of this model are almost endless.

\section{Severe FSHD-like mouse model}

While the moderate model decline can be assayed over 2 weeks, the severe model is only useful for short-term analyses, as the DUX4-induced pathology is so severe that the mice require sacrifice no later than SD10. These mice do not show any signs of recovery. As in the moderate model, there are consistently different levels of transgene recombination and DUX4-fl expression among different anatomical muscles (Fig. 1b). However, different muscles show the same patterns as in the moderate model (e.g., soleus is highest and quadriceps is lowest for both models), supporting the idea that accessibility to the TMX that is responsible for the variability. In addition, as seen for both the mild and moderate models, females and males of the severe model showed sex-specific differences, with females again being more severely affected. Upon induction of DUX4-fl expression, eMyHC expression (Figs. 11 and S13), apoptosis (Figs. 13 and S15), and fibrosis (Figs. 14 and S16) appear by SD6 and are all at the highest levels for any model at SD9. Treadmill stamina is significantly affected by SD6, and mice are immobile by SD9, with muscles producing $\sim 25 \%$ of the force generated by ACTA1-MCM controls and $\sim 50 \%$ of the force produced in the moderate model (Figs. 4, 5, and S7). These markers for pathology are supported by global differential gene expression profiles that show greater enrichment for induced genes relating to apoptosis, immune response, and cell cycle, compared to the moderate model, while many muscle biology genes are significantly decreased (Fig. 7).

\section{Conclusions}

The goal in this study was to generate differing levels of FSHD-like severity using our FLExD mouse model and characterize the progression of pathology in ways useful to those performing preclinical testing of candidate DUX4-targeted therapeutics. We have provided an initial molecular, phenotypic, physiological, histological, and transcriptome characterization of three severity levels of FSHD-like model mice based on three levels of mosaic DUX4-fl expression in skeletal muscles. A key feature of these models is that the ACTA1-MCM;FLEXD bitransgenic mice express chronic low-level mosaic and skeletal muscle-specific DUX4-fl mRNA and protein without any TMX induction throughout their lifetime. Thus, the moderate and severe models are not introducing DUX4 expression to a naive system, instead providing a situation similar to the bursts of DUX4 expression seen in FSHD myocytes [21]. It is well documented that cells from asymptomatic FSHD subjects express DUX4 and cells from relatively healthy muscle biopsies from clinically affected FSHD patients express significant levels of DUX4 $[10,18,19]$. Thus, these models are recapitulating how we envision the DUX4 expression situation in FSHD whereby DUX4 levels in skeletal muscles correlate with pathology [35]. Thus, these bi-transgenic FSHD-like models allow investigators to recapitulate the 
chronic, low-levels of DUX4 using the mild model, or investigate more severe DUX4-mediated pathology by an investigator-controlled increase in DUX4 expression using TMX. In addition, the bi-transgenic model is the only available DUX4 model mouse that lives a normal lifespan (up to 2 years) while continually expressing detectable levels of mosaic DUX4-FL protein throughout its skeletal musculature [78, 91, 113], making it the only choice for long-term therapeutic knockdown studies of DUX4-fl.

Overall, these dose-dependent DUX4-fl FSHD-like phenotypic mouse models strongly support the DUX4 misexpression model for levels of DUX4 expression mediating levels of FSHD pathology $[17,20]$ and provide a useful and highly flexible tool for performing FSHD preclinical testing of therapeutic approaches targeting DUX4-fl mRNA and protein. Importantly for future analyses, we have shown sex-specific differences, anatomical muscle-specific differences, and model-specific differences that must be taken into account when using these FSHD-like mice. Within a single mouse, one can assess differentially affected muscles. Studying both sexes from a cross provides more fine-tuning of effects as well, with females being slightly but significantly more affected than the males. This provides even greater flexibility and utility for the model as a tool for studying FSHD and testing potential therapeutic approaches targeting the DUX4-fl mRNA and/or protein.

\section{Supplementary information}

Supplementary information accompanies this paper at https://doi.org/10. 1186/s13395-020-00227-4.

Additional file 1: Figure S1. FLEXDUX4 transgenic mice kept in different housing facilities acquire different mouth and gut microbiomes and have differing alopecia and Gl health. Figure S2. Mosaic tamoxifen dose-dependent recombination in gastrocnemius muscle of ACTA1$M C M ; R 26^{N Z G}$ bi-transgenic mice. Figure S3. Increased TMX dosage leads to increased mosaic recombination in skeletal muscle of ACTA1-

$M C M ; R 26^{N Z G}$ bi-transgenic mice. Figure S4. There is no significant difference in the transgene recombination rate between male and female ACTA7-MCM/FLEXD bi-transgenic FSHD-like mice. Figure S5. Quantification of DUX4-FL protein positive myonuclei. Figure S6. The moderate and severe FSHD-like mouse models show significant weight loss. Figure S7. Maximum isometric forces of the female FSHD-like mouse models. Figure S8. Maximum and specific isometric forces of the male mild and severe FSHD-like mouse models. Figure 59. Pax7 target genes are not significantly misexpressed in the FSHD-like mouse models. Figure $\mathbf{S 1 0 .}$ $\mathrm{GO}$ enrichment analysis of differentially expressed genes ( $>2$-fold) in the different FSHD-like severity model mice. Figure S11. Fiber number per cross-section does not significantly change with severity. Figure S12. The heart is not affected by TMX treatment in control or bi-transgenic animals. Figure S13. Quantification of eMyHC positive muscle cells in different FSHD-like mouse models. Figure S14. Mstn gene mRNA expression decreases with increased DUX4-fl expression in the FSHD-like mouse models. Figure S15. Quantification of TUNEL positive nuclei in FSHD-like mouse models. Figure S16. Quantification of SR staining shows significant fibrosis in late stages of the moderate and severe FSHD-like mouse models. Figure S17. Cardiac muscle from FSHD-like mouse models shows no signs of increased fibrosis.
Additional file 2: Table S1. Significantly altered gene expression in FSHD-like models

Additional file 3: Table S2. Differentially expressed genes Additional file 4: Table S3. Intersection of misregulated genes in models with FSHD patients

Additional file 5: Table S4. GO term superterms

Additional file 6: Table S5. GO superterm genes

Additional file 7: Table S6. MISO alternative splicing analysis for SE and $\mathrm{Rl}$

\section{Abbreviations}

DPI: Days post-injection; EDL: Extensor digitorum longus; FLEXD: FLEXDUX4; FSHD: Facioscapulohumeral muscular dystrophy; GA: Gastrocnemius; H\&E: Hematoxylin \& eosin; IF: Immunofluorescence; IP: Intraperitoneal; MCM: MerCreMer; MD: Moderate model day; Mstn: Myostatin; nLacZ: Nuclear B-galactosidase; PCR: Polymerase chain reaction; qRT-PCR: Quantitative reverse transcriptase PCR; QUA: Quadriceps; RNA-seq: RNA sequencing; S.D.: Standard deviation; SD: Severe model day; SOL: Soleus; TA: Tibialis anterior; TMX: Tamoxifen; TUNEL: Terminal deoxynucleotide transferase dUTP nick end labeling

\section{Acknowledgements}

We thank Jennifer Burgess; Chris Carrino; Mick Hitchcock, Ph.D.; Dr. Bill R. Lewis Sr. and Duncan Lewis; and Daniel P. Perez for supporting our FSHD mouse work. We thank Dr. Charis Himeda for helpful discussions and editing the manuscript. This work was funded by grants from the Chris Carrino Foundation for FSHD, the FSH Society (FSHS-22012-01), the Muscular Dystrophy Association (MDA383364), and the National Institute of Arthritis and Musculoskeletal and Skin Diseases (R01 AR070432 and R21 AR070438) to $\mathrm{PLJ}$ and from the National Institute of Neurological Disorders and Stroke P01 NS069539 to RKB. PLJ is supported by the Mick Hitchcock, Ph.D. Endowed Chair of Medical Biochemistry at UNR Med. RKB is a Scholar of The Leukemia \& Lymphoma Society.

\section{Authors' contributions}

TJ conceived of the study, performed experiments, analyzed data, and wrote the manuscript. GW analyzed data and wrote the manuscript. PB performed experiments and analyzed data. SS performed experiments and analyzed data. MR performed experiments and analyzed data. RW performed experiments, analyzed data, and wrote the manuscript. DB conceived of the study and wrote the manuscript. RB analyzed data and wrote the manuscript. PJ conceived of the study, analyzed data, and wrote the manuscript. All authors read and approved the final manuscript.

\section{Availability of data and materials}

Most data generated and analyzed during this study are included in the manuscript and supplemental data. Any data not included is available from the corresponding authors upon request. Raw RNA-seq data generated in this study has been deposited in the NCBI GEO database under accession number GSE122562.

\section{Ethics approval and consent to participate}

All animal procedures were approved by the local IACUC committee at the University of Nevada, Reno (\#0701).

\section{Consent for publication}

Not applicable

\section{Competing interests}

The authors declare that they have no competing interests.

\section{Author details}

'Department of Pharmacology, School of Medicine, University of Nevada, Reno, Reno, NV 89557, USA. ${ }^{2}$ Computational Biology Program, Public Health Sciences Division, Fred Hutchinson Cancer Research Center, Seattle, WA 98109, USA. ${ }^{3}$ Basic Sciences Division, Fred Hutchinson Cancer Research Center, Seattle, WA 98109, USA. ${ }^{4}$ Current Address: The Cancer Science Institute of Singapore, National University of Singapore, Singapore, Singapore. 


\section{Received: 21 February 2020 Accepted: 5 March 2020}

\section{Published online: 11 April 2020}

\section{References}

1. Padberg GW, Frants RR, Brouwer OF, Wijmenga C, Bakker E, Sandkuijl LA. Facioscapulohumeral muscular dystrophy in the Dutch population. Muscle Nerve. 1995;2:S81-S84.

2. van der Maarel SM, Miller DG, Tawil R, Filippova GN, Tapscott SJ. Facioscapulohumeral muscular dystrophy: consequences of chromatin relaxation. Curr Opin Neurol. 2012;25:614-20.

3. Deenen JC, Arnts $\mathrm{H}$, van der Maarel SM, Padberg GW, Verschuuren J, Bakker E, Weinreich SS, Verbeek AL, van Engelen BG. Population-based incidence and prevalence of facioscapulohumeral dystrophy. Neurology. 2014;83:1056-9.

4. Prevalence and incidence of rare diseases: Bibliographic data [http://www. orpha.net/orphacom/cahiers/docs/GB/Prevalence_of_rare_diseases_by_ alphabetical_list.pdf].

5. Gabriels J, Beckers MC, Ding H, De Vriese A, Plaisance S, van der Maarel SM, Padberg GW, Frants RR, Hewitt JE, et al. Nucleotide sequence of the partially deleted D4Z4 locus in a patient with FSHD identifies a putative gene within each 3.3 kb element. Gene. 1999;236:25-32.

6. van Overveld PG, Lemmers RJ, Sandkuijl LA, Enthoven L, Winokur ST, Bakels F, Padberg GW, van Ommen GJ, Frants RR, et al. Hypomethylation of D4Z4 in 4q-linked and non-4q-linked facioscapulohumeral muscular dystrophy. Nat Genet. 2003;35:315-7.

7. Kowaljow V, Marcowycz A, Ansseau E, Conde CB, Sauvage S, Matteotti C, Arias C, Corona ED, Nunez NG, et al. The DUX4 gene at the FSHD1A locus encodes a pro-apoptotic protein. Neuromuscul Disord. 2007;17:611-23.

8. de Greef JC, Lemmers RJ, van Engelen BG, Sacconi S, Venance SL, Frants RR, Tawil R, van der Maarel SM. Common epigenetic changes of D4Z4 in contraction-dependent and contraction-independent FSHD. Hum Mutat. 2009;30:1449-59.

9. Snider L, Geng LN, Lemmers RJ, Kyba M, Ware CB, Nelson AM, Tawil R, Filippova GN, van der Maarel SM, et al. Facioscapulohumeral dystrophy: incomplete suppression of a retrotransposed gene. PLoS Genet. 2010;6: e1001181.

10. Jones Tl, King OD, Himeda CL, Homma S, Chen JC, Beermann ML, Yan C, Emerson CP Jr, Miller JB, et al. Individual epigenetic status of the pathogenic D4Z4 macrosatellite correlates with disease in facioscapulohumeral muscular dystrophy. Clin Epigen. 2015;7:37.

11. Himeda $\mathrm{CL}$, Jones PL. The genetics and epigenetics of facioscapulohumeral muscular dystrophy. Annu Rev Genomics Hum Genet. 2019;20:265-91.

12. Johnson NE, Statland JM. FSHD1 or FSHD2: That is the question: the answer: it's all just FSHD. Neurology. 2019;92:881-2.

13. Wijmenga C, Hewitt JE, Sandkuijl LA, Clark LN, Wright TJ, Dauwerse HG, Gruter AM, Hofker MH, Moerer P, et al. Chromosome 4q DNA rearrangements associated with facioscapulohumeral muscular dystrophy. Nat Genet. 1992;2:26-30

14. van Deutekom JC, Wijmenga C, van Tienhoven EA, Gruter AM, Hewitt JE, Padberg GW, van Ommen GJ, Hofker MH, Frants RR. FSHD associated DNA rearrangements are due to deletions of integral copies of a $3.2 \mathrm{~kb}$ tandemly repeated unit. Hum Mol Genet. 1993;2:2037-42.

15. Lemmers RJ, Tawil R, Petek LM, Balog J, Block GJ, Santen GW, Amell AM, van der Vliet PJ, Almomani R, et al. Digenic inheritance of an SMCHD1 mutation and an FSHD-permissive D4Z4 allele causes facioscapulohumeral muscular dystrophy type 2. Nat Genet. 2012;44:1370-4.

16. van den Boogaard ML, Lemmers RJ, Balog J, Wohlgemuth M, Auranen M, Mitsuhashi S, van der Vliet PJ, Straasheijm KR, van den Akker RF, et al. Mutations in DNMT3B modify epigenetic repression of the D4Z4 repeat and the penetrance of facioscapulohumeral dystrophy. Am J Hum Genet. 2016; 98:1020-9

17. Lemmers RJ, van der Vliet PJ, Klooster R, Sacconi S, Camano P, Dauwerse JG, Snider L, Straasheijm KR, van Ommen GJ, et al. A unifying genetic model for facioscapulohumeral muscular dystrophy. Science. 2010;329:1650-3.

18. Jones TI, Chen JC, Rahimov F, Homma S, Arashiro P, Beermann ML, King $\mathrm{OD}$, Miller JB, Kunkel LM, et al. Facioscapulohumeral muscular dystrophy family studies of DUX4 expression: evidence for disease modifiers and a quantitative model of pathogenesis. Hum Mol Genet. 2012;21:4419-30.

19. Lemmers RJ, Goeman JJ, Van Der Vliet PJ, Van Nieuwenhuizen MP, Balog J, Vos-Versteeg M, Camano P, Ramos Arroyo MA, Jerico I, et al. Inter-individual differences in CpG methylation at D4Z4 correlate with clinical variability in FSHD1 and FSHD2. Hum Mol Genet. 2015:24:659-69.

20. Tawil R, van der Maarel SM, Tapscott SJ. Facioscapulohumeral dystrophy: the path to consensus on pathophysiology. Skelet Muscle. 2014;4:12.

21. Rickard AM, Petek LM, Miller DG. Endogenous DUX4 expression in FSHD myotubes is sufficient to cause cell death and disrupts RNA splicing and cell migration pathways. Hum Mol Genet. 2015;24:5901-14.

22. Dixit M, Ansseau E, Tassin A, Winokur S, Shi R, Qian H, Sauvage S, Matteotti C, van Acker AM, et al. DUX4, a candidate gene of facioscapulohumeral muscular dystrophy, encodes a transcriptional activator of PITX1. Proc Natl Acad Sci U S A. 2007;104:18157-62

23. De laco A, Planet E, Coluccio A, Verp S, Duc J, Trono D. DUX-family transcription factors regulate zygotic genome activation in placental mammals. Nat Genet. 2017;49:941-5.

24. Hendrickson PG, Dorais JA, Grow EJ, Whiddon JL, Lim JW, Wike CL, Weaver $B D$, Pflueger C, Emery BR, et al. Conserved roles of mouse DUX and human DUX4 in activating cleavage-stage genes and MERVL/HERVL retrotransposons. Nat Genet. 2017;49:925-34.

25. Whiddon JL, Langford AT, Wong CJ, Zhong JW, Tapscott SJ. Conservation and innovation in the DUX4-family gene network. Nat Genet. 2017;49:93540.

26. Yao Z, Snider L, Balog J, Lemmers RJ, Van Der Maarel SM, Tawil R, Tapscott SJ. DUX4-induced gene expression is the major molecular signature in FSHD skeletal muscle. Hum Mol Genet. 2014;23:5342-52.

27. Campbell AE, Belleville A, Resnick R, Shadle SC, Tapscott SJ. Facioscapulohumeral dystrophy: activating an early embryonic transcriptional program in human skeletal muscle. Hum Mol Genet. 2018.

28. Tassin A, Laoudj-Chenivesse D, Vanderplanck C, Barro M, Charron S, Ansseau E, Chen YW, Mercier J, Coppee F, et al. DUX4 expression in FSHD muscle cells: how could such a rare protein cause a myopathy? I Cell Mol Med. 2013;17:76-89

29. Padberg GW: Facioscapulohumeral Disease [thesis]. Leiden, the Netherlands: Leiden University; 1982.

30. Wang LH, Tawil R. Facioscapulohumeral dystrophy. Curr Neurol Neurosci Rep. 2016;16:66

31. Himeda CL, Debarnot C, Homma S, Beermann ML, Miller JB, Jones PL, Jones TI. Myogenic enhancers regulate expression of the facioscapulohumeral muscular dystrophy associated DUX4 gene. Mol Cell Biol. 2014;34:1942-55.

32. Haynes $P$, Bomsztyk K, Miller DG. Sporadic DUX4 expression in FSHD myocytes is associated with incomplete repression by the PRC2 complex and gain of H3K9 acetylation on the contracted D4Z4 allele. Epigenetics Chromatin. 2018;11:47.

33. Geng LN, Yao Z, Snider L, Fong AP, Cech JN, Young JM, van der Maarel SM, Ruzzo WL, Gentleman RC, et al. DUX4 activates germline genes, retroelements, and immune mediators: Implications for facioscapulohumeral dystrophy. Dev Cell. 2012;22:38-51.

34. Jagannathan S, Shadle SC, Resnick R, Snider L, Tawil RN, van der Maarel SM, Bradley RK, Tapscott SJ. Model systems of DUX4 expression recapitulate the transcriptional profile of FSHD cells. Hum Mol Genet. 2016;25:4419-31.

35. Wang LH, Friedman SD, Shaw D, Snider L, Wong CJ, Budech CB, Poliachik $\mathrm{SL}$, Gove NE, Lewis LM, et al. MRI-informed muscle biopsies correlate MRI with pathology and DUX4 target gene expression in FSHD. Hum Mol Genet. 2019;28:476-86.

36. Homma S, Beermann ML, Boyce FM, Miller JB. Expression of FSHD-related DUX4-FL alters proteostasis and induces TDP-43 aggregation. Annals of clinical and translational neurology. 2015;2:151-66.

37. Feng $Q$, Snider $L$, Jagannathan $S$, Tawil R, van der Maarel SM, Tapscott SJ, Bradley RK. A feedback loop between nonsense-mediated decay and the retrogene DUX4 in facioscapulohumeral muscular dystrophy. eLife. 2015;4

38. Vanderplanck C, Ansseau E, Charron S, Stricwant N, Tassin A, LaoudjChenivesse D, Wilton SD, Coppee F, Belayew A. The FSHD strophic myotube phenotype is caused by DUX4 expression. PLoS One. 2011;6:e26820.

39. Dmitriev P, Bou Saada Y, Dib C, Ansseau E, Barat A, Hamade A, Dessen P, Robert T, Lazar V, et al. DUX4-induced constitutive DNA damage and oxidative stress contribute to aberrant differentiation of myoblasts from FSHD patients. Free Radic Biol Med. 2016;99:244-58.

40. Bosnakovski D, Toso EA, Hartweck LM, Magli A, Lee HA, Thompson ER, Dandapat A, Perlingeiro RCR, Kyba M. The DUX4 homeodomains mediate inhibition of myogenesis and are functionally exchangeable with the Pax homeodomain. J Cell Sci. 2017. 
41. Bosnakovski D, Gearhart MD, Toso EA, Ener ET, Choi SH, Kyba M. Low level DUX4 expression disrupts myogenesis through deregulation of myogenic gene expression. Sci Rep. 2018;8:16957.

42. Wuebbles RD, Long SW, Hanel ML, Jones PL. Testing the effects of FSHD candidate gene expression in vertebrate muscle development. Int J Clin Exp Pathol. 2010;3:386-400

43. Wallace LM, Garwick SE, Mei W, Belayew A, Coppee F, Ladner KJ, Guttridge D, Yang J, Harper SQ. DUX4, a candidate gene for facioscapulohumeral muscular dystrophy, causes p53-dependent myopathy in vivo. Ann Neurol. 2011:69:540-52.

44. Shadle SC, Zhong JW, Campbell AE, Conerly ML, Jagannathan S, Wong CJ, Morello TD, van der Maarel SM, Tapscott SJ. DUX4-induced dsRNA and MYC mRNA stabilization activate apoptotic pathways in human cell models of facioscapulohumeral dystrophy. PLoS Genet. 2017;13:e1006658.

45. Himeda $\mathrm{CL}$, Jones $\mathrm{Tl}$, Jones PL. Facioscapulohumeral muscular dystrophy as a model for epigenetic regulation and disease. Antioxidants \& redox signaling. 2015;22:1463-82.

46. Schnutgen F, Doerflinger N, Calleja C, Wendling O, Chambon P, Ghyselinck NB. A directional strategy for monitoring Cre-mediated recombination at the cellular level in the mouse. Nat Biotechnol. 2003;21:562-5.

47. Schnutgen F, De-Zolt S, Van Sloun P, Hollatz M, Floss T, Hansen J, Altschmied J, Seisenberger C, Ghyselinck NB, et al. Genomewide production of multipurpose alleles for the functional analysis of the mouse genome. Proc Natl Acad Sci U S A. 2005;102:7221-6.

48. Jones T, Jones PL. A cre-inducible DUX4 transgenic mouse model for investigating facioscapulohumeral muscular dystrophy. PLoS One. 2018;13: e0192657.

49. Wallace LM, Garwick-Coppens SE, Tupler R, Harper SQ. RNA interference improves myopathic phenotypes in mice over-expressing FSHD region gene 1 (FRG1). Mol Ther. 2011;19:2048-54.

50. Marsollier AC, Ciszewski L, Mariot V, Popplewell L, Voit T, Dickson G, Dumonceaux J. Antisense targeting of 3 ' end elements involved in DUX4 mRNA processing is an efficient therapeutic strategy for facioscapulohumeral dystrophy: a new gene-silencing approach. Hum Mo Genet. 2016;25:1468-78.

51. Ansseau E, Vanderplanck C, Wauters A, Harper SQ, Coppee F, Belayew A. Antisense oligonucleotides used to target the DUX4 mRNA as therapeutic approaches in FaciosScapuloHumeral muscular Dystrophy (FSHD). Genes (Basel). 2017:8

52. Peart N, Wagner EJ. A distal auxiliary element facilitates cleavage and polyadenylation of Dux4 mRNA in the pathogenic haplotype of FSHD. Hum Genet. 2017;136:1291-301.

53. Snider L, Asawachaicharn A, Tyler AE, Geng LN, Petek LM, Maves L, Mille DG, Lemmers RJ, Winokur ST, et al. RNA transcripts, miRNA-sized fragments and proteins produced from D4Z4 units: new candidates for the pathophysiology of facioscapulohumeral dystrophy. Hum Mol Genet. 2009; 18:2414-30.

54. Lemmers RJ, van der Vliet PJ, van der Gaag KJ, Zuniga S, Frants RR, de Knijff $P$, van der Maarel SM. Worldwide population analysis of the $4 q$ and $10 q$ subtelomeres identifies only four discrete interchromosomal sequence transfers in human evolution. Am J Hum Genet. 2010;86:364-77.

55. McCarthy JJ, Srikuea R, Kirby TJ, Peterson CA, Esser KA. Inducible Cre transgenic mouse strain for skeletal muscle-specific gene targeting. Skelet Muscle. 2012;2:8

56. Yamamoto M, Shook NA, Kanisicak O, Yamamoto S, Wosczyna MN, Camp JR, Goldhamer DJ. A multifunctional reporter mouse line for Cre- and FLPdependent lineage analysis. Genesis. 2009;47:107-14.

57. Jones TI, Himeda CL, Perez DP, Jones PL. Large family cohorts of lymphoblastoid cells provide a new cellular model for investigating facioscapulohumeral muscular dystrophy. Neuromuscul Disord. 2017;27:221-38.

58. Smith LR, Barton ER. Collagen content does not alter the passive mechanical properties of fibrotic skeletal muscle in $\mathrm{mdx}$ mice. Am J Physiol Cell Physiol. 2014;306:C889-98.

59. Sperringer JE, Grange RW. In vitro assays to determine skeletal muscle physiologic function. Methods Mol Biol. 2016;1460:271-91.

60. Van Ry PM, Wuebbles RD, Key M, Burkin DJ. Galectin-1 protein therapy prevents pathology and improves muscle function in the $\mathrm{mdx}$ mouse model of Duchenne muscular dystrophy. Mol Ther. 2015;23:1285-97.

61. Meyer LR, Zweig AS, Hinrichs AS, Karolchik D, Kuhn RM, Wong M, Sloan CA, Rosenbloom KR, Roe G, et al. The UCSC Genome Browser database: extensions and updates 2013. Nucleic Acids Res. 2013;41:D64-9.
62. Flicek P, Ahmed I, Amode MR, Barrell D, Beal K, Brent S, Carvalho-Silva D, Clapham P, Coates G, et al. Ensembl 2013. Nucleic Acids Res. 2013;41:D4855.

63. Katz Y, Wang ET, Airoldi EM, Burge CB. Analysis and design of RNA sequencing experiments for identifying isoform regulation. Nat Methods. 2010;7:1009-15.

64. Dvinge H, Ries RE, llagan JO, Stirewalt DL, Meshinchi S, Bradley RK. Sample processing obscures cancer-specific alterations in leukemic transcriptomes. Proc Natl Acad Sci U S A. 2014;111:16802-7.

65. Li B, Dewey CN. RSEM: accurate transcript quantification from RNA-Seq data with or without a reference genome. BMC Bioinformatics. 2011;12:323.

66. Langmead B, Trapnell C, Pop M, Salzberg SL. Ultrafast and memory-efficient alignment of short DNA sequences to the human genome. Genome Biol. 2009;10:R25

67. Trapnell C, Pachter L, Salzberg SL. TopHat: discovering splice junctions with RNA-Seq. Bioinformatics. 2009;25:1105-11.

68. Robinson MD, Oshlack A. A scaling normalization method for differential expression analysis of RNA-seq data. Genome Biol. 2010;11:R25.

69. Wagenmakers EJ, Lodewyckx T, Kuriyal H, Grasman R. Bayesian hypothesis testing for psychologists: a tutorial on the Savage-Dickey method. Cogn Psychol. 2010;60:158-89.

70. Young MD, Wakefield MJ, Smyth GK, Oshlack A. Gene ontology analysis for RNA-seq: accounting for selection bias. Genome Biol. 2010;11:R14.

71. Huber W, Carey VJ, Gentleman R, Anders S, Carlson M, Carvalho BS, Bravo HC, Davis S, Gatto L, et al. Orchestrating high-throughput genomic analysis with Bioconductor. Nat Methods. 2015;12:115-21.

72. dplyr: A Grammar of Data Manipulation. R Package Version 0.4.3. [http:// cran.r-project.org/package=dplyr ].

73. Wickham H: ggplot2: Elegant graphics for data analysis: Springer-Verlag New York; 2009

74. Helicobacter species [(https://www.criver.com/sites/default/files/resources/ HelicobacterspeciesTechnicalSheet.pdf)].

75. Sundberg JP, Schofield PN. Living inside the box: environmental effects on mouse models of human disease. Dis Model Mech. 2018;11.

76. Treuting PM, Clifford CB, Sellers RS, Brayton CF. Of mice and microflora: considerations for genetically engineered mice. Vet Pathol. 2012;49:44-63.

77. Gary RK, Kindell SM. Quantitative assay of senescence-associated betagalactosidase activity in mammalian cell extracts. Anal Biochem. 2005;343: 329-34.

78. Krom YD, Thijssen PE, Young JM, den Hamer B, Balog J, Yao Z, Maves L, Snider L, Knopp P, et al. Intrinsic epigenetic regulation of the D4Z4 macrosatellite repeat in a transgenic mouse model for FSHD. PLoS Genet. 2013;9:e1003415.

79. Moorwood C, Liu M, Tian Z, Barton ER. Isometric and eccentric force generation assessment of skeletal muscles isolated from murine models of muscular dystrophies. Journal of visualized experiments. JoVE. 2013:e50036.

80. Sharma V, Harafuji N, Belayew A, Chen YW. DUX4 differentially regulates transcriptomes of human rhabdomyosarcoma and mouse C2C12 Cells. PLoS One. 2013:8:e64691.

81. Knopp P, Krom YD, Banerji CR, Panamarova M, Moyle LA, den Hamer B, van der Maarel SM, Zammit PS. DUX4 induces a transcriptome more characteristic of a less-differentiated cell state and inhibits myogenesis. J Cell Sci. 2016:129:3816-31.

82. Young JM, Whiddon JL, Yao Z, Kasinathan B, Snider L, Geng LN, Balog J, Tawil R, van der Maarel SM, et al. DUX4 binding to retroelements creates promoters that are active in FSHD muscle and testis. PLoS Genet. 2013;9: e1003947.

83. Banerji CRS, Panamarova M, Hebaishi H, White RB, Relaix F, Severini S, Zammit PS. PAX7 target genes are globally repressed in facioscapulohumeral muscular dystrophy skeletal muscle. Nat Commun 2017:8:2152.

84. Banerji CRS, Panamarova M, Pruller J, Figeac N, Hebaishi H, Fidanis E, Saxena A, Contet J, Sacconi S, et al. Dynamic transcriptomic analysis reveals suppression of PGC1alpha/ERRalpha drives perturbed myogenesis in facioscapulohumeral muscular dystrophy. Hum Mol Genet. 2019;28:1244-59.

85. Bosnakovski D, Xu Z, Gang EJ, Galindo CL, Liu M, Simsek T, Garner HR, AghaMohammadi S, Tassin A, et al. An isogenetic myoblast expression screen identifies DUX4-mediated FSHD-associated molecular pathologies. EMBO J. 2008;27:2766-79.

86. Haynes P, Kernan K, Zhou SL, Miller DG. Expression patterns of FSHDcausing DUX4 and myogenic transcription factors PAX3 and PAX7 are 
spatially distinct in differentiating human stem cell cultures. Skelet Muscle. 2017;7:13.

87. Banerji CRS, Zammit PS. PAX7 target gene repression is a superior FSHD biomarker than DUX4 target gene activation, associating with pathological severity and identifying FSHD at the single-cell level. Hum Mol Genet. 2019; 28:2224-36.

88. Blake JA, Ziman MR. Pax genes: regulators of lineage specification and progenitor cell maintenance. Development. 2014;141:737-51.

89. Mitsuhashi H, Mitsuhashi S, Lynn-Jones T, Kawahara G, Kunkel LM. Expression of DUX4 in zebrafish development recapitulates facioscapulohumeral muscular dystrophy. Hum Mol Genet. 2013;22:568-77.

90. Lek A, Rahimov F, Jones PL, Kunkel LM. Emerging preclinical animal models for FSHD. Trends Mol Med. 2015;21:295-306.

91. Bosnakovski D, Chan SSK, Recht OO, Hartweck LM, Gustafson CJ, Athman LL, Lowe DA, Kyba M. Muscle pathology from stochastic low level DUX4 expression in an FSHD mouse model. Nat Comm. 2017;8:550.

92. Dandapat A, Bosnakovski D, Hartweck LM, Arpke RW, Baltgalvis KA, Vang D, Baik J, Darabi R, Perlingeiro RC, et al. Dominant lethal pathologies in male mice engineered to contain an X-linked DUX4 transgene. Cell reports. 2014; 8:1484-96.

93. Corona ED, Jacquelin D, Gatica L, Rosa AL. Multiple protein domains contribute to nuclear import and cell toxicity of DUX4, a candidate pathogenic protein for facioscapulohumeral muscular dystrophy. PLoS One. 2013;8:e75614

94. Arahata K, Ishihara T, Fukunaga H, Orimo S, Lee JH, Goto K, Nonaka I. Inflammatory response in facioscapulohumeral muscular dystrophy (FSHD): immunocytochemical and genetic analyses. Muscle Nerve Suppl. 1995:S5666.

95. Tasca G, Pescatori M, Monforte M, Mirabella M, lannaccone E, Frusciante R, Cubeddu T, Laschena F, Ottaviani P, et al. Different molecular signatures in magnetic resonance imaging-staged facioscapulohumeral muscular dystrophy muscles. PLoS One. 2012;7:e38779.

96. Frisullo G, Frusciante R, Nociti V, Tasca G, Renna R, lorio R, Patanella AK, lannaccone $\mathrm{E}$, Marti A, et al. CD8(+) T cells in facioscapulohumeral muscular dystrophy patients with inflammatory features at muscle MRI. J Clin Immunol. 2010.

97. Statland JM, Shah B, Henderson D, van der Maarel S, Tapscott SJ, Tawil R. Muscle pathology grade for facioscapulohumeral muscular dystrophy biopsies. Muscle Nerve. 2015

98. Folker ES, Baylies MK. Nuclear positioning in muscle development and disease. Front Physiol. 2013;4:363

99. Schiaffino S, Rossi AC, Smerdu V, Leinwand LA, Reggiani C. Developmental myosins: expression patterns and functional significance. Skelet Muscle. 2015;5:22.

100. McPherron AC, Lawler AM, Lee SJ. Regulation of skeletal muscle mass in mice by a new TGF-beta superfamily member. Nature. 1997;387:83-90.

101. Murgia M, Nagaraj N, Deshmukh AS, Zeiler M, Cancellara P, Moretti I, Reggiani C, Schiaffino S, Mann M. Single muscle fiber proteomics reveals unexpected mitochondrial specialization. EMBO Rep. 2015;16:387-95.

102. Esser K, Gunning P, Hardeman E. Nerve-dependent and -independent patterns of mRNA expression in regenerating skeletal muscle. Dev Biol. 1993;159:173-83

103. Sartore S, Gorza L, Schiaffino S. Fetal myosin heavy chains in regenerating muscle. Nature. 1982;298:294-6.

104. Carraro U, Catani C, Saggin L, Zrunek M, Szabolcs M, Gruber H, Streinzer W, Mayr W, Thoma H. Isomyosin changes after functional electrostimulation of denervated sheep muscle. Muscle Nerve. 1988;11:1016-28.

105. Bosnakovski D, Choi SH, Strasser JM, Toso EA, Walters MA, Kyba M. Highthroughput screening identifies inhibitors of DUX4-induced myoblast toxicity. Skelet Muscle. 2014;4:4.

106. Statland JM, Odrzywolski KJ, Shah B, Henderson D, Fricke AF, van der Maarel SM, Tapscott SJ, Tawil R. Immunohistochemical characterization of facioscapulohumeral muscular dystrophy muscle biopsies. Journal of neuromuscular diseases. 2015;2:291-9.

107. Schessl J, Zou Y, Bonnemann CG. Congenital muscular dystrophies and the extracellular matrix. Semin Pediatr Neurol. 2006;13:80-9.

108. Klingler W, Jurkat-Rott K, Lehmann-Horn F, Schleip R. The role of fibrosis in Duchenne muscular dystrophy. Acta Myol. 2012;31:184-95.

109. Lieber RL, Ward SR. Cellular mechanisms of tissue fibrosis. 4. Structural and functional consequences of skeletal muscle fibrosis. Am J Physiol Cell Physiol. 2013;305:C241-52.
110. MacDonald EM, Cohn RD. TGFbeta signaling: its role in fibrosis formation and myopathies. Curr Opin Rheumatol. 2012;24:628-34.

111. Whittaker P, Kloner RA, Boughner DR, Pickering JG. Quantitative assessment of myocardial collagen with picrosirius red staining and circularly polarized light. Basic Res Cardiol. 1994;89:397-410.

112. Clapp J, Mitchell LM, Bolland DJ, Fantes J, Corcoran AE, Scotting PJ, Armour JA, Hewitt JE. Evolutionary conservation of a coding function for D4Z4, the tandem DNA repeat mutated in facioscapulohumeral muscular dystrophy. Am J Hum Genet. 2007;81:264-79.

113. Giesige CR, Wallace LM, Heller KN, Eidahl JO, Saad NY, Fowler AM, Pyne NK, Al-Kharsan M, Rashnonejad A, et al. AAV-mediated follistatin gene therapy improves functional outcomes in the TIC-DUX4 mouse model of FSHD. JCl Insight. 2018;3.

\section{Publisher's Note}

Springer Nature remains neutral with regard to jurisdictional claims in published maps and institutional affiliations.
Ready to submit your research? Choose BMC and benefit from:

- fast, convenient online submission

- thorough peer review by experienced researchers in your field

- rapid publication on acceptance

- support for research data, including large and complex data types

- gold Open Access which fosters wider collaboration and increased citations

- maximum visibility for your research: over $100 \mathrm{M}$ website views per year

At $\mathrm{BMC}$, research is always in progress.

Learn more biomedcentral.com/submissions 